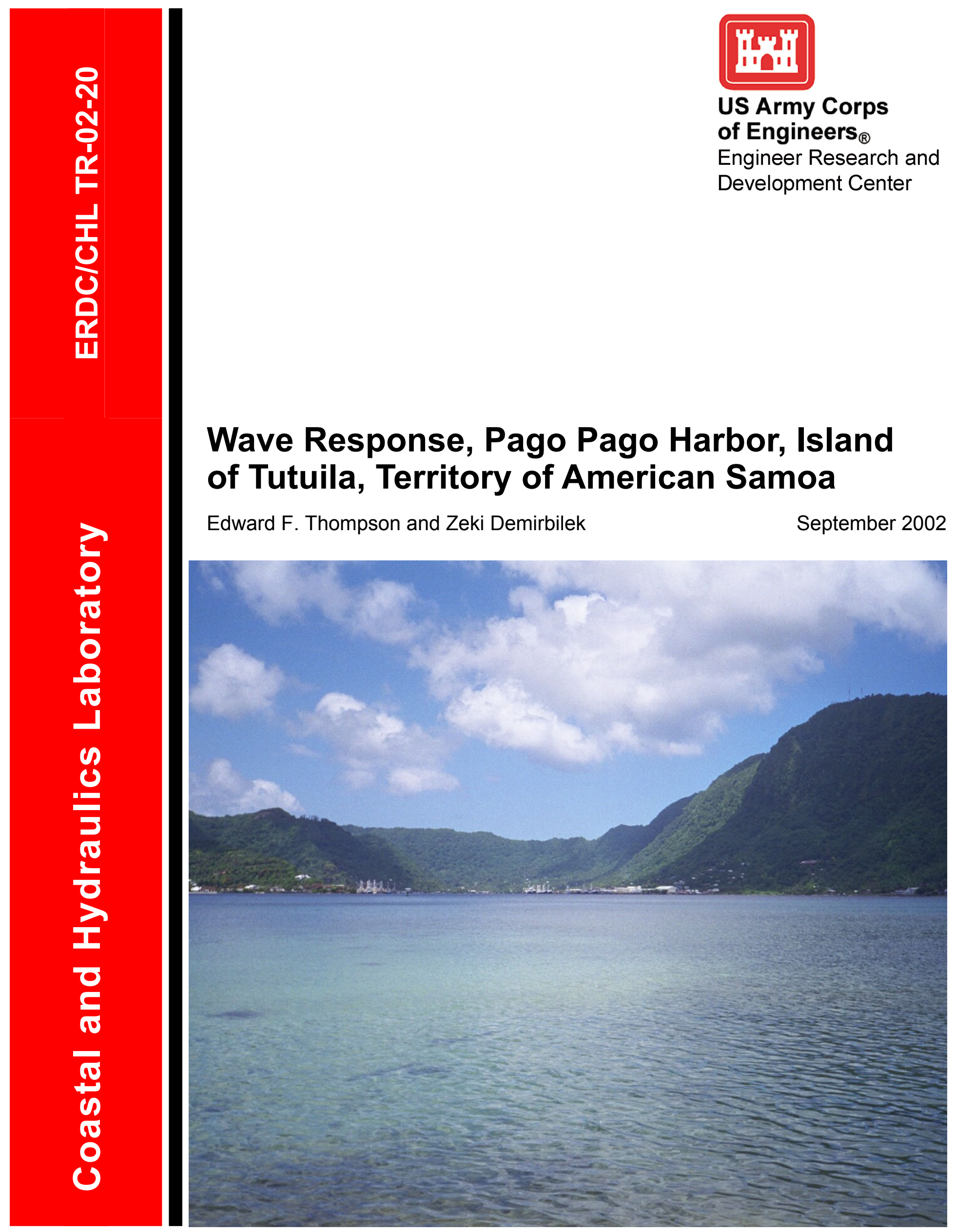


The contents of this report are not to be used for advertising, publication, or promotional purposes. Citation of trade names does not constitute an official endorsement or approval of the use of such commercial products.

The findings of this report are not to be construed as an official Department of the Army position, unless so designated by other authorized documents. 


\section{Wave Response, Pago Pago Harbor, Island of Tutuila, Territory of American Samoa}

by Edward F. Thompson, Zeki Demirbilek

Coastal and Hydraulics Laboratory

U.S. Army Engineer Research and Development Center 3909 Halls Ferry Road

Vicksburg, MS 39180-6199

Final report

Approved for public release; distribution is unlimited 


\section{Contents}

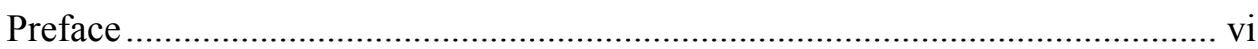

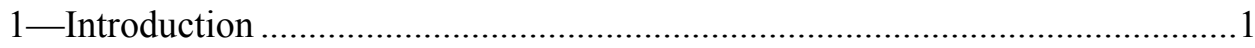

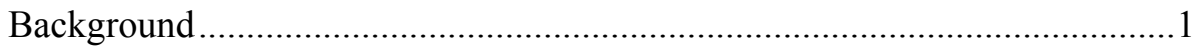

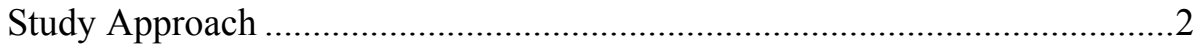

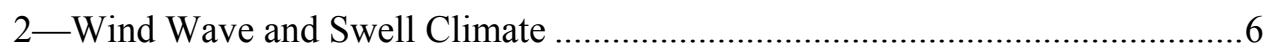

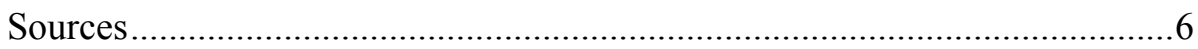

Deepwater Wave Climate .................................................................

Wave Climate at Pago Pago Harbor ..........................................................

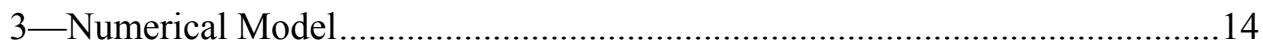

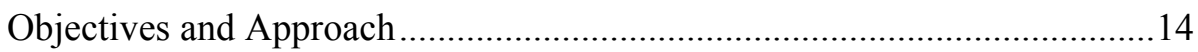

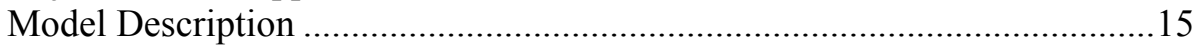

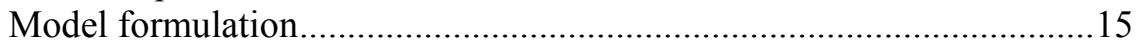

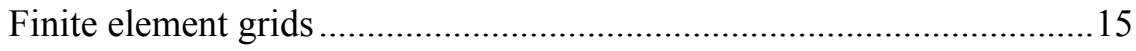

Table 3 Parameter Values Used in CGWAVE.......................................17

Test Procedures and Calculations .........................................................18

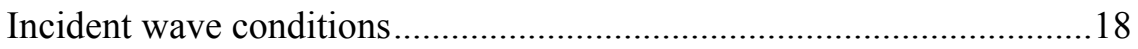

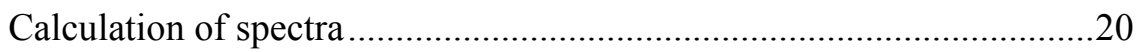

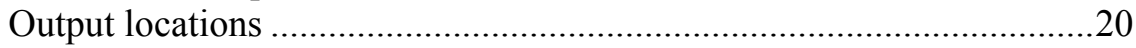

4-Harbor Response to Wind Waves and Swell.............................................22

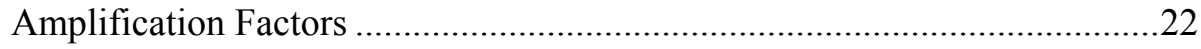

Evaluation against Operational Criteria for Wind Waves and Swell.............23

Wave and Water Levels for Design .........................................................27

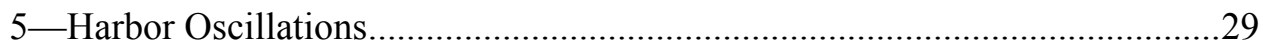

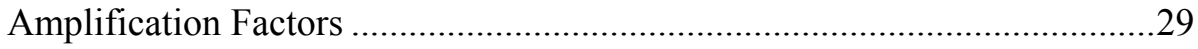

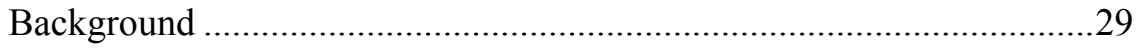

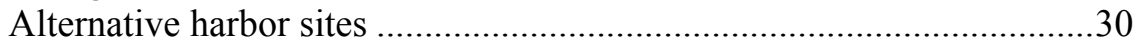

Evaluation against Operational Criteria for Long Waves ..............................38 


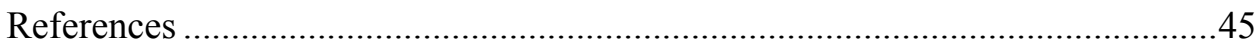

SF 298

\section{List of Figures}

Figure 1. Location map of study area ......................................................

Figure 2. Location map for Tutuila and Pago Pago Harbor.............................

Figure 3. Location map for study sites ................................................ 5

Figure 4. Wave hindcast summary, Jun 85-May 90, $H_{s}(\mathrm{~m})$ vs $\theta_{p} \ldots \ldots \ldots \ldots \ldots . . . .9$

Figure 5. Wave hindcast summary, Jun 85-May 90, $T_{p}$ vs $\theta_{p} \ldots \ldots \ldots \ldots \ldots \ldots \ldots . . . . . . .10$

Figure 6. Wave hindcast summary, Jun 85-May 90, $H_{s}$ vs $T_{p} \ldots \ldots \ldots \ldots \ldots \ldots \ldots . \ldots 11$

Figure 7. Wave hindcast summary, Jun 85-May 90, wind speed vs wind

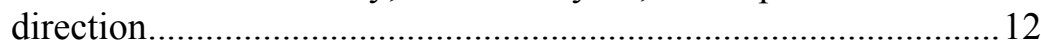

Figure 8. Wave height rose, deepwater hindcast, Jun 85-May 90 ...............13

Figure 9. Wave period rose, deepwater hindcast, Jun 85-May 90 …...........13

Figure 10. Model bathymetry, existing harbor ............................................ 16

Figure 11. Illustration of model grid, Anasosopo site …...............................17

Figure 12. Incident shortwave directions modeled ......................................19

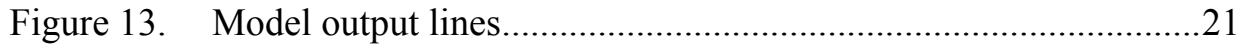

Figure 14. Wave height amplification factor, average for 6- to 12-sec

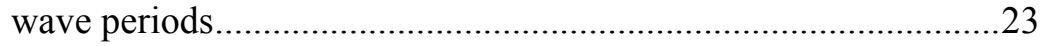

Figure 15. Wave height amplification factor based on incident wave

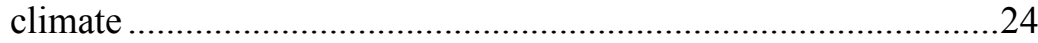

Figure 16. $H_{s}$ exceeding 10 percent and 1 percent of time at study sites........26

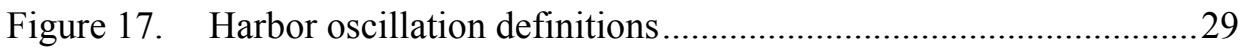

Figure 18. Longwave response, existing harbor ..........................................31

Figure 19. Resonant longwave amplification factor contours, Peaks 1-3.......32 
Figure 20. Resonant longwave amplification factor contours, Peaks 4-6.......33

Figure 21. Resonant longwave amplification factor contours, Peaks 7-9.......34

Figure 22. Resonant longwave phase contours, Peaks 1-3 ….........................35

Figure 23. Resonant longwave phase contours, Peaks 4-6 …........................36

Figure 24. Resonant longwave phase contours, Peaks 7-9 ….......................37

Figure 25. Resonant longwave velocity contours, Peaks 1-3 ........................40

Figure 26. Resonant longwave velocity contours, Peaks 4-6 ........................41

Figure 27. Resonant longwave velocity contours, Peaks 7-9 _.....................42

\section{List of Tables}

Table 1. Sources for Wave Climate Information........................................ 6

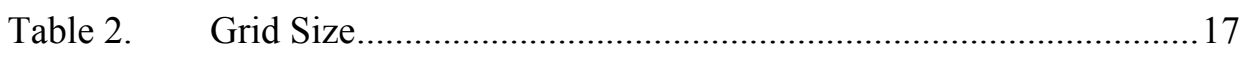

Table 3. Parameter Values Used in CGWAVE .......................................... 17

Table 4. Summary of Incident Shortwave Conditions .............................. 18

Table 5. Summary of Incident Longwave Conditions................................20

Table 6. $H_{s}$ Exceeding 10 Percent and 1 Percent of time at Study Sites .....26

Table 7. Extreme Wave and Water Levels ...............................................28 


\section{Preface}

This report describes procedures and results of a wave response study for Pago Pago Harbor, Island of Tutuila, Territory of American Samoa. The study was performed in support of long-range planning for additional harbor facilities on Tutuila Island. The study was performed by the U.S. Army Engineer Research and Development Center (ERDC), Coastal and Hydraulics Laboratory (CHL), for the U.S. Army Engineer District, Honolulu (HED). The study was conducted during the period February through July 2002. Mr. Stan Boc, HED, was the study manager and point of contact.

The investigation reported herein was conducted by Drs. Edward F. Thompson and Zeki Demirbilek, CHL. The final report was prepared by Dr. Thompson.

This study was performed under the general supervision of Mr. Thomas W. Richardson, Director, CHL. Direct supervision of this project was provided by Mr. Dennis G. Markle, Chief, Coastal Harbors and Structures Branch.

At the time of publication of this report, Dr. James R. Houston was Director of ERDC, and COL John W. Morris III, EN, was Commander and Executive Director.

The contents of this report are not to be used for advertising, publication, or promotional purposes. Citation of trade names does not constitute an official endorsement or approval of the use of such commercial products. 


\section{Introduction}

\section{Background}

The Territory of American Samoa consists of seven islands located in the South Pacific Ocean at approximately $170 \mathrm{~W}$ longitude and $14 \mathrm{~S}$ latitude. The Islands lie east-northeast of Australia and northeast of New Zealand (Figure 1). They fall about mid-way along a line between New Zealand and Hawaii. Their separation is about $4,300 \mathrm{~km}$ (2,700 miles) from the nearest Australian coast and $3,200 \mathrm{~km}$ (2,000 miles) from the nearest New Zealand coast.

The islands Tutuila, Aunuu, Ofu, Olosega, and Tau comprise the principal populated areas and together cover an area of $199 \mathrm{sq} \mathrm{km}(77 \mathrm{sq} \mathrm{mi})$. Tutuila is the largest of the five islands (Figure 2). The small island of Aunuu lies less than a mile from the east end of Tutuila. The Manu'a Group, consisting of Ofu, Olosega, and Tau, are located $160 \mathrm{~km}(60 \mathrm{mi})$ east of Tutuila and Aunuu. All five islands are volcanic, with typically narrow coastal areas and steep mountains. Fringing coral reefs are common around the islands and can extend to $610 \mathrm{~m}(2,000 \mathrm{ft})$ out from the shoreline (Sea Engineering, Inc., and Belt Collins Hawaii 1994). These reefs are typically very shallow and some are exposed at low tide.

Western Samoa, geographically part of the Samoa Islands group but politically separate from the Territory of American Samoa, is less than $75 \mathrm{~km}$ (50 miles) west of Tutuila. The International Date Line passes just west of Western Samoa.

Pago Pago Harbor, the principal harbor area of the Territory of American Samoa, is located on the southern side of Tutuila (Figure 2). The harbor is deep, with typical depths of $60 \mathrm{~m}(200 \mathrm{ft})$ along its main axis. Tuna canneries, a wharf, and government buildings are located on the inner harbor shores, where the embayment has turned to an east-west orientation and is well-protected from the open sea. Besides Pago Pago Harbor, Tutuila's coast is dotted with smaller embayments; most are located on the north shore of the island. Aunuu and the Manu'a Group lack natural embayments, although small harbors (Aunuu Small Boat Harbor, Ofu Harbor, and Tau Small Boat Harbor) have been constructed by the U.S. Army Corps of Engineers. 
The Territory of American Samoa typically experiences a deepwater wave climate with significant heights ranging from 1 to $3 \mathrm{~m}$ (3 to $10 \mathrm{ft}$ ) and peak wave periods of 5 to $9 \mathrm{sec}$. Peak periods of up to $25 \mathrm{sec}$ can occur, but available information indicates that the longer peak periods appear infrequently. The wave climate varies little with season and is relatively consistent from year to year.

The low-latitude location of the Territory of American Samoa is favorable for tropical storm and hurricane formation and passage. Historically, the area has experienced infrequent, but devastating, major hurricanes. During the atypical period 1987 through 1991, three intense hurricanes severely impacted the area. Storm damage included: village damage and destruction, road washout, harbor destruction, and crop damage (Sea Engineering, Inc. and Belt Collins Hawaii 1994). A coastal inundation study was initiated to calculate hurricane stagefrequency hydrographs for five of the seven islands (Militello, Scheffner, and Thompson 2002).

Extreme wave conditions for Western Samoa were estimated by Kinhill, Riedel \& Byrne (1992) in relation to coastal revetment design. Although the study was not aimed at south-facing coasts, these estimates have some relevance for the Territory of American Samoa. Hurricanes and other tropical storms were considered separately from the general wave climate. For the general wave climate, significant height with 5-year return period was $3.1 \mathrm{~m}(10.2 \mathrm{ft})$, increaseing to $3.5 \mathrm{~m}(11.5 \mathrm{ft})$ for 50 -year return period. When hurricanes and other tropical storms were included in the design wave estimate, the 5-year significant height was $3.75 \mathrm{~m}(12.3 \mathrm{ft})$ and the 50 -year height was $7.3 \mathrm{~m}$ (23.9 ft). The study results suggest that hurricanes and tropical storms are a minor concern over a typical period of several years, but a major concern over long return periods.

The astronomical tide range at Pago Pago Harbor between mean high water and mean low water is $0.8 \mathrm{~m}(2.5 \mathrm{ft})$. Extreme low water extends $0.8 \mathrm{~m}(2.5 \mathrm{ft})$ below mean low water.

The present harbor facilities on Tutuila are expected to be insufficient to meet future needs of the Territory of American Samoa. The U.S. Army Engineer District, Honolulu (HED), is investigating possible new sites for dock facilities on Tutuila. The present study objective, in support of HED's effort, is to analyze wave response at alternative sites under preliminary consideration. All sites included in this study are within the Pago Pago Harbor embayment.

\section{Study Approach}

The study described in this report was performed by the U.S. Army Engineer Research and Development Center (ERDC), Coastal and Hydraulics Laboratory (CHL), in support of HED planning for harbor needs on Tutuila. The approach consisted of the following components: 
a. Characterize incident wave climate from available sources.

b. Develop numerical wave model CGWAVE application to cover study areas.

c. Use the numerical model to investigate alternative harbor sites.

Wave information around the Samoa Islands is very limited. For this study, wind wave and swell climate was characterized with information from Kinhill, Riedel \& Byrne (1992). Key sources were nondirectional buoy data from the south side of Western Samoa and a 5-year hindcast for deep water, open ocean in the same general area. Wave climate information is presented in Chapter 2.

Numerical wave model CGWAVE, the present state-of-the-art CHL model for harbor wave response studies, was set up to cover the entire Pago Pago Harbor embayment and an area seaward of the entrance extending beyond shoal areas to relatively deep water. Existing bathymetry was used. Four alternative sites were considered (Figure 3). Development of the numerical model application and test procedures are described in Chapter 3.

Response of the alternative sites to wind waves and swell (short waves) is presented in Chapter 4. Harbor oscillation characteristics (response to long waves) are presented in Chapter 5. For both short and long waves, the harbor response is related to wave climate and to relevant operational criteria at commercial piers.

Conclusions and recommendations are given in Chapter 6. This chapter is followed by references. 


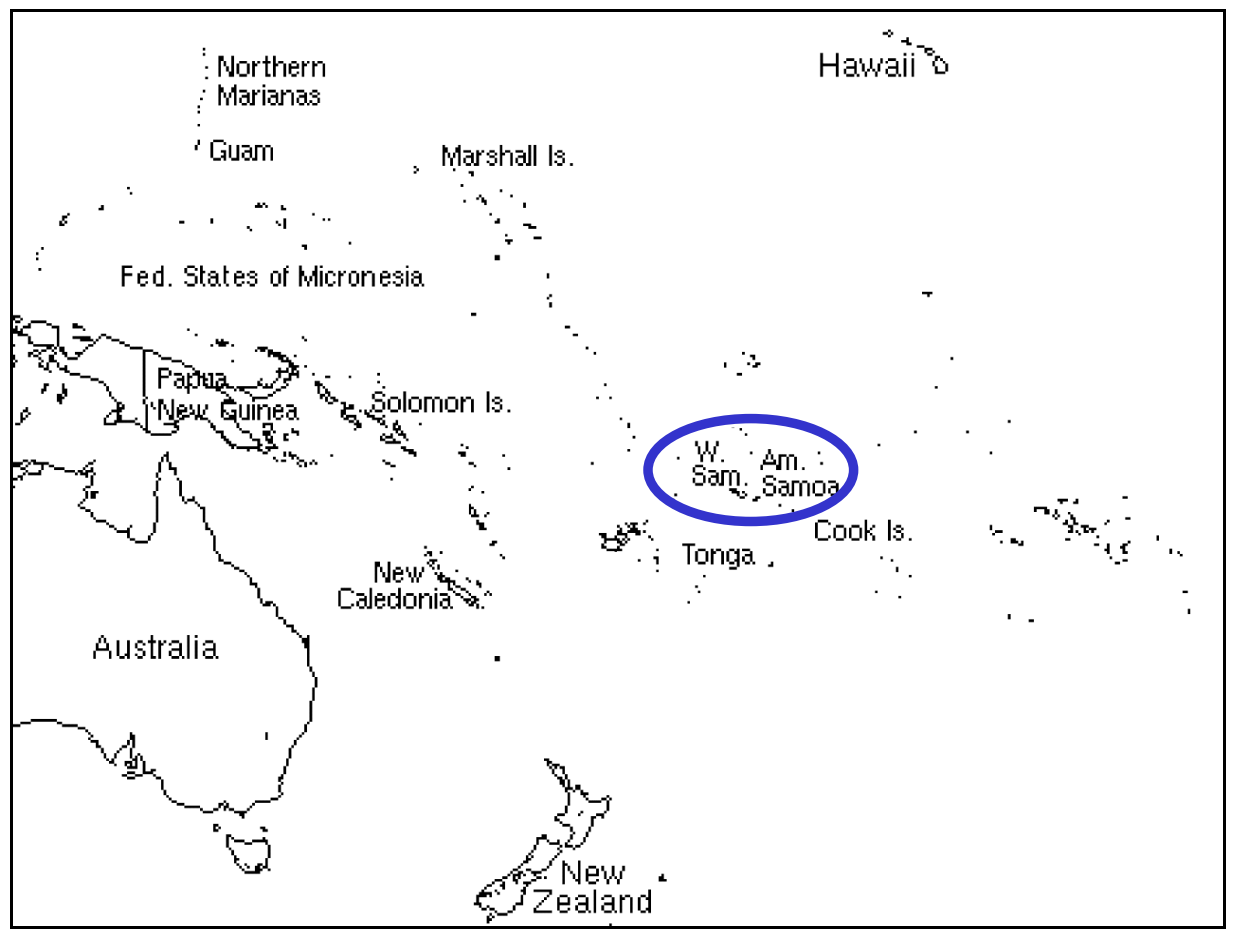

Figure 1. Location map of study area 


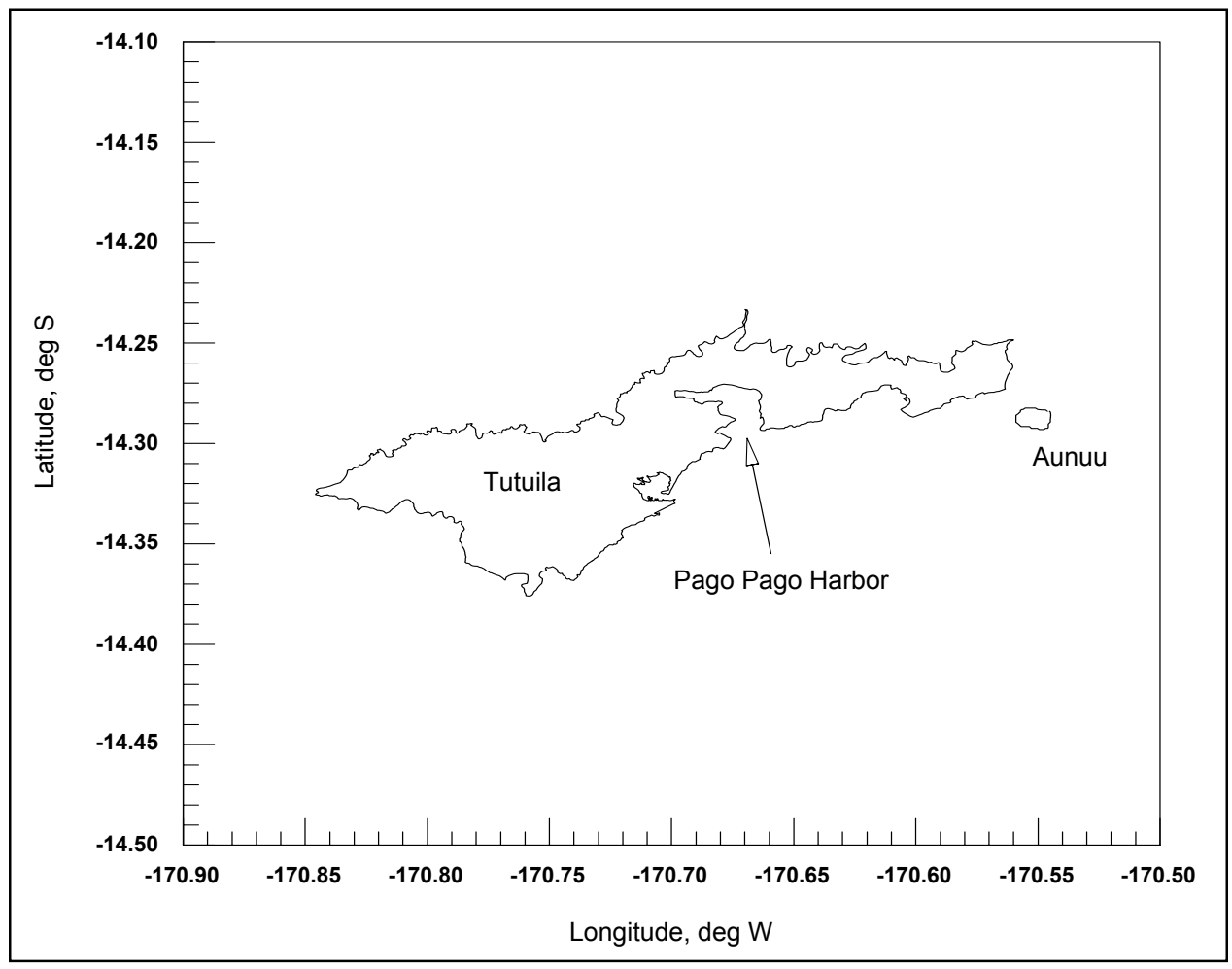

Figure 2. Location map for Tutuila and Pago Pago Harbor

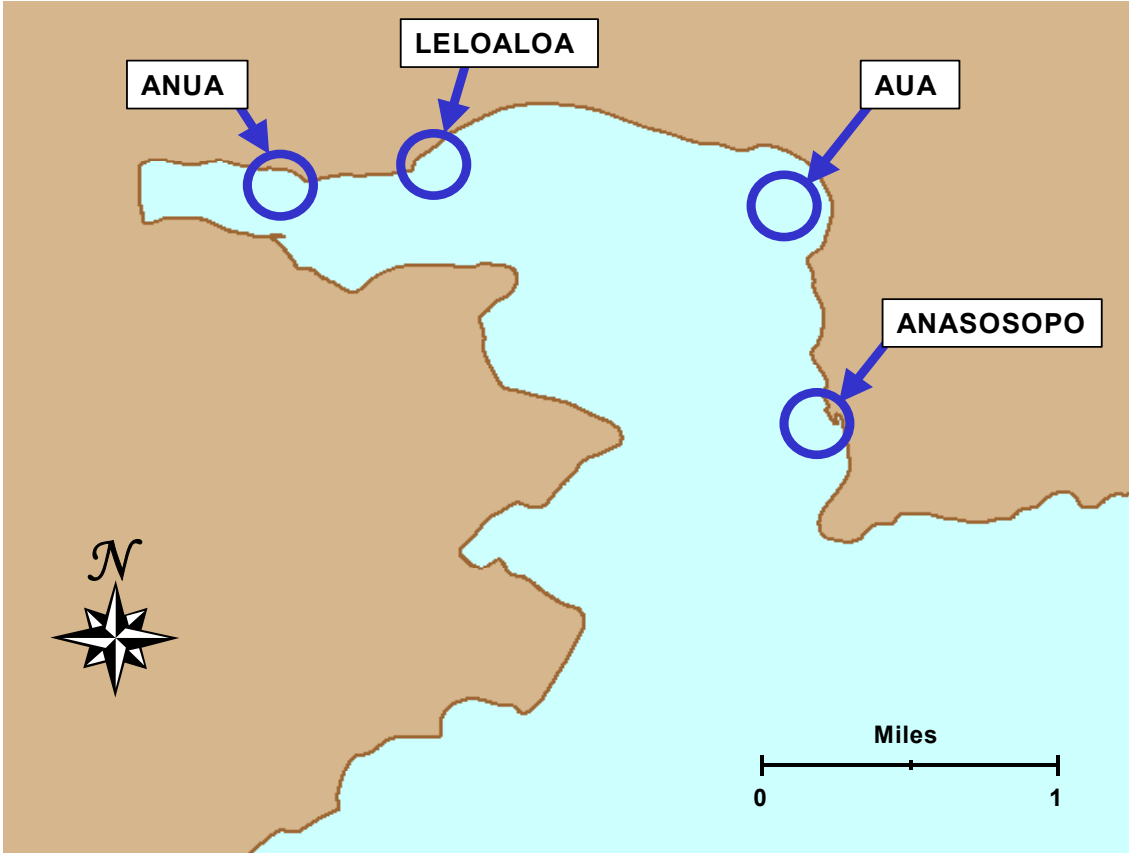

Figure 3. Location map for study sites 


\section{Wind Wave and Swell Climate}

\section{Sources}

Two sources of wind wave and swell information were available to develop wave climate outside the entrance to Pago Pago Harbor embayment (Table 1). Both were originally generated for Western Samoa (Kinhill, Riedel \& Byrne 1992). No wave information was available directly for the Tutuila coast and Western Samoa is sufficiently nearby that a similar offshore wave climate can be expected.

The first source was a nondirectional accelerometer buoy just south of the Western Samoa Islands. These measurements were collected by the South Pacific Applied Geoscience Commission for the Government of Western Samoa. The initial period of deployment was September 1989 to April 1990. The gage was redeployed in May 1990 to a location $37 \mathrm{~km}$ (23 miles) further south. Data from only the first deployment were available for this study. The gage was sheltered from the northwest and east but exposed to the northeast through a gap between islands. The gage had full exposure to waves from east southeast through west. This exposure, particularly the open southern exposure, is fairly similar to that for the entrance to Pago Pago Harbor embayment.

The second source of wind wave and swell information was a global hindcast from which information was saved at a point near Western Samoa. The hindcast covered the 5-year time period June 1985 to May 1990. Hindcast wave information was developed by Oceanroutes (Australia) using the Global Spectral Ocean Wave Model (GSOWM). Since the model grid resolution was $2.5 \mathrm{deg}$ latitude and longitude, the hindcast includes no representation of small islands such as the Samoa Islands. Hindcast information near the Samoa Islands represents deepwater waves in open water at this general location in the Pacific Ocean. Tutuila is less than one grid cell east and south of this point and the hindcasts can be considered representative there, as well.

\begin{tabular}{||l|l|l|l||}
\hline \hline \multicolumn{4}{||l||}{$\begin{array}{l}\text { Table } 1 \\
\text { Sources for Wave Climate Information }\end{array}$} \\
\hline \hline Source & Years & Latitude (deg S) & Longitude (deg W) \\
\hline \hline Western Samoa buoy & $1989-90$ & 13.9 & 172.2 \\
\hline Global hindcast & $1985-90$ & 12.5 & 172.0 \\
\hline
\end{tabular}




\section{Deepwater Wave Climate}

The 5-year global hindcast includes the parameters significant wave height, $H_{s}$, peak period, $T_{p}$, and peak direction, $\theta_{p}$, (dominant direction for wave energy within the frequency band of peak energy). All three parameters are necessary for an adequate description of the wave climate incident to the south side of Tutuila. Wave direction, which is not available from the buoy gage, has a key impact on how much incident wave energy propagates to different locations inside the Pago Pago Harbor embayment.

Fortunately, the hindcasts overlap the time period of the first buoy gage deployment. Kinhill, Riedel \& Byrne (1992) included a comparison of hindcast and measured $H_{s}$ and $T_{p}$ during the months of overlap. They concluded that the hindcast wave climate was sufficiently validated by buoy data, despite their differences in location and exposure. Even for Hurricane Ofa, the extreme event during the overlap period, the hindcast compared reasonably well with the buoy. The hindcast peak $H_{s}$ was $9.0 \mathrm{~m}(30 \mathrm{ft})$ versus $7.3 \mathrm{~m}(24 \mathrm{ft})$ measured at the buoy. The corresponding $T_{p}$ was $9.0 \mathrm{sec}$ from the buoy and $12 \mathrm{sec}$ from the hindcast.

Wave climate summaries of the 5-year hindcast are given by Kinhill, Riedel $\&$ Byrne (1992). Percent occurrence information for $H_{s}$ versus $\theta_{p}$ shows that $H_{s}$ is generally less than $3 \mathrm{~m}(9.8 \mathrm{ft})$ and most waves come from the general direction of east (i.e., ENE-ESE) (Figure 4). Waves from the south, southwest and west occur infrequently. The figure indicates that the higher waves generally come from directions between west and north. From southerly and southeasterly directions, the directions of greatest exposure for the Pago Pago Harbor embayment, wave heights are relatively mild, with most $H_{s}$ less than $2.5 \mathrm{~m}(8.2 \mathrm{ft})$ and no occurrences of $H_{s}$ greater than $3 \mathrm{~m}$.

Percent occurrence information for $T_{p}$ versus $\theta_{p}$ shows that nearly 80 percent of the $T_{p}$ values are $9 \mathrm{sec}$ or less (Figure 5). Longer $T_{p}$ conditions are also present in the wave climate, with periods up to $25 \mathrm{sec}$ and longer. For the directions of greatest exposure for Pago Pago Harbor embayment, nearly all $T_{p}$ occurrences are $13 \mathrm{sec}$ or less and the great majority are $9 \mathrm{sec}$ or less.

Percent occurrence information for $H_{s}$ versus $T_{p}$ shows little relationship between the two parameters for the lower, more common wave conditions $\left(H_{s}\right.$ less than or equal to $2 \mathrm{~m}(6.6 \mathrm{ft}$ ) (Figure 6 ). For higher wave conditions, the shorter $T_{p}$ values become less common and a preference for $T_{p}$ values in the 8 - to 9 -sec band or longer is indicated.

Percent occurrence information for wind speed versus wind direction is also available from the hindcasts (Figure 7). The summary indicates that winds are mild much of the time, with speeds of $5 \mathrm{~m} / \mathrm{sec}(10 \mathrm{kts})$ or less occurring over 70 percent of the time. Wind speeds over $10 \mathrm{~m} / \mathrm{sec}(20 \mathrm{kts})$ are rare. Winds are generally from east through southeast. 


\section{Wave Climate at Pago Pago Harbor}

The incident wave climate needed for modeling wave response in the Pago Pago Harbor embayment is a deepwater climate which takes into account sheltering by the Tutuila Island land mass. The 5 -year hindcast can be modified to provide the needed wave climate. The study area is exposed to waves coming from east clockwise to southwest. Other wave approach directions are blocked by Tutuila Island.

Available hindcast information is limited in that the summaries do not give percent occurrences of three-parameter, $H_{s}, T_{p}$, and $\theta_{p}$, combinations. A threeparameter incident wave climate was developed, based primarily on percent occurrence information for $T_{p}$ versus $\theta_{p}$ (Figure 5). Only wave directions of open exposure were included, which accounted for nearly 50 percent of the hindcast wave climate. Percent occurrences for these directions were increased proportionately so they would total 100 percent. This approach essentially assumes that hindcast events with $\theta_{p}$ from sheltered directions also include energy from exposed directions and should not be considered as calms along the south coast of Tutuila. A presence of multiple wave trains with different propagation directions has been common at exposed ocean locations and would be expected at the Samoa Islands (Thompson 1980). This approach was judged to be the best for developing wave climate for the south side of Tutuila because: (a) details of the wave climate are not available and a definitive analysis is not possible; (b) the sheltered directions indicate waves as energetic or more energetic than the exposed directions, and (c) the buoy at Western Samoa, which was mostly sheltered from the north, still compared reasonably well with hindcast $H_{s}$ values over a wide variety of wave conditions.

Within each bin of the $T_{p}$ versus $\theta_{p}$ percent occurrence table, values of $H_{s}$ were distributed as described in the $H_{s}$ versus $T_{p}$ percent occurrence table (Figure 6). For example, 3.89 percent of the occurrences fell in the bin for $\theta_{p}=\mathrm{E}$ and $T_{p}=$ "to $6 \mathrm{sec}$ " (Figure 5). For $T_{p}=$ "to $6 \mathrm{sec}$," Figure 6 shows that 0.09 percent of the cases have $H_{s}=0.5$ to $1.0 \mathrm{~m}, 11.37$ percent have $H_{s}=1.0$ to $1.5 \mathrm{~m}$, etc. Proportionately, 0.2 percent of the cases with $T_{p}=$ "to $6 \mathrm{sec}$ " have $H_{s}=0.5$ to $1.0 \mathrm{~m}, 29.7$ percent have $H_{s}=1.0$ to $1.5 \mathrm{~m}$, etc.

The wave climate developed as described above was reviewed to ensure that a reasonable representation of the hindcast information was preserved. A rose of $H_{s}$ shows the percentage of cases coming from different directions (Figure 8). The length of the radial bar in each direction shows the percentage from that direction. As in the previous hindcast figures, the most common wave direction is from the east southeast (37 percent of the cases). The width of the radial bars indicates $H_{s}$ band. The lowest $H_{s}$ bands are shown nearest the center of the rose. The radial bars become more narrow toward the outer end of each bar, indicating increasing wave heights. A similar rose for $T_{p}$ is shown in Figure 9. 


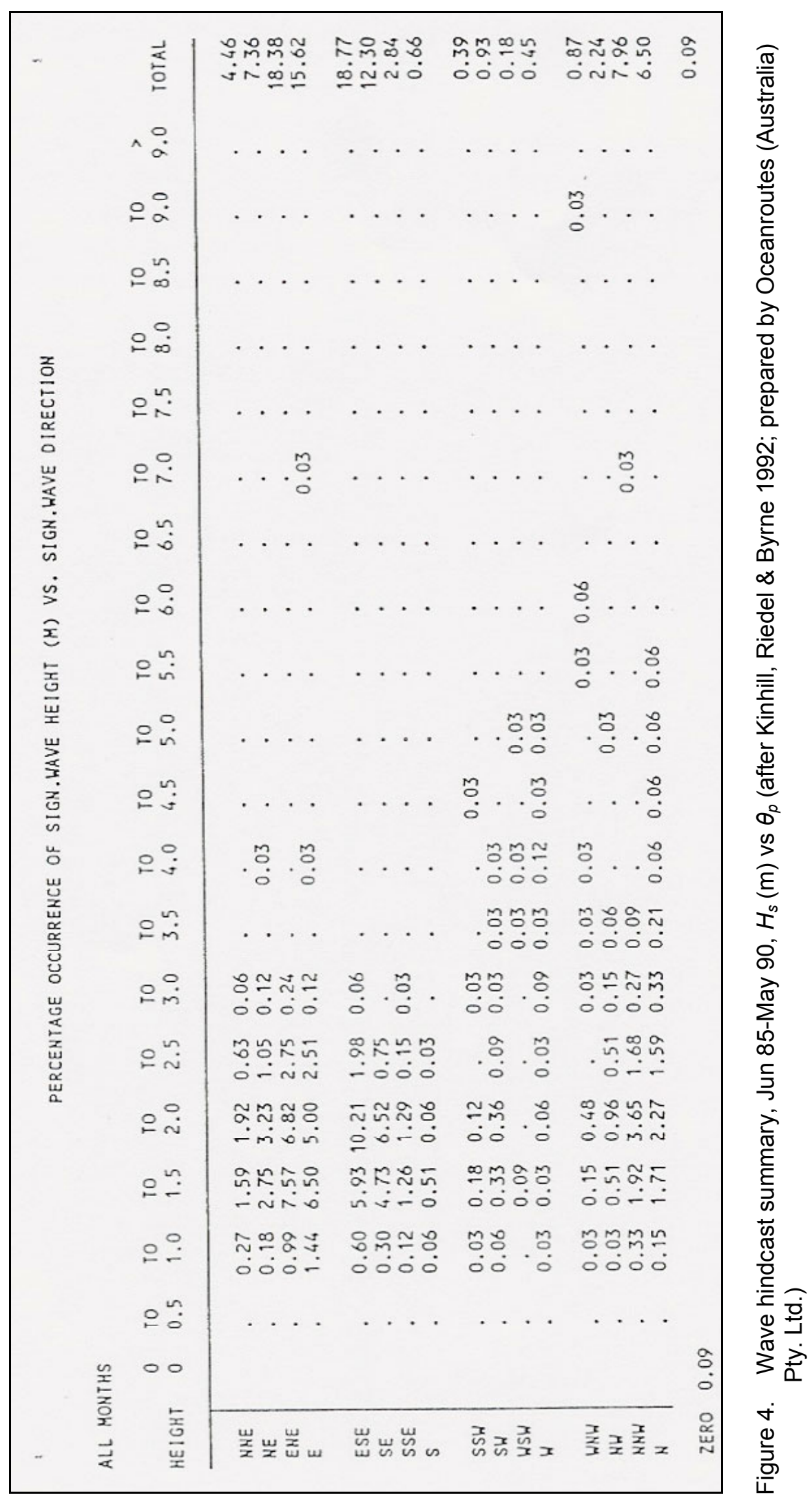




\begin{tabular}{|c|c|c|c|c|c|c|c|c|c|}
\hline & & 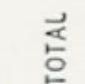 & 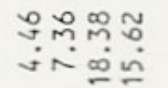 & 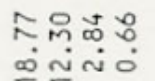 & man & $\begin{array}{l}\hat{\infty} \approx 200 \\
0 \sim \sim \\
0\end{array}$ & : & & \\
\hline ô & & $\wedge \stackrel{\sim}{\sim}$ & $\cdots$ & $\cdots$ & $\ldots$ & 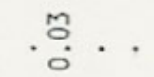 & & $\ddot{o}$ & \\
\hline $\begin{array}{l}\tilde{\omega} \\
8\end{array}$ & & 은 & $\cdots$ & $\cdots$ & $\cdots$ &.$\stackrel{m}{0}$. & & mọ & \\
\hline $\begin{array}{l}\bar{x} \\
w \\
\alpha \\
x\end{array}$ & & 은요 & \begin{tabular}{l}
$\infty \pi 0 \%$. \\
\hdashline 00. \\
00
\end{tabular} & $\cdots$ & :̊ํㅇ. & 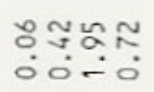 & & $\stackrel{乏}{m}$ & \\
\hline $\begin{array}{l}\text { ü } \\
\dot{\omega}\end{array}$ & & 은 & \begin{tabular}{l}
$n \sim 20$ \\
\hdashline 0 \\
00
\end{tabular} & $\stackrel{m}{\circ} . .$. & $\stackrel{m}{\circ} . \stackrel{m}{\circ}$ & å & & ¿o & \\
\hline 존 & & 은 & $\stackrel{\circ}{\circ}$. & $\ldots$ & $\ldots$ & $\begin{array}{l}\simeq 000 \\
000\end{array}$ & & 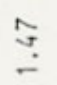 & \\
\hline 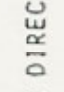 & & 으ㄴㅡㅡ & 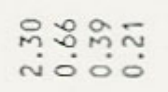 & 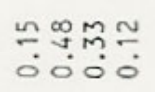 & 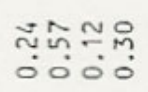 & 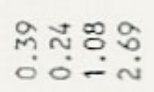 & & $\grave{\dddot{0}}$ & \\
\hline 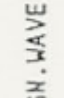 & & 은 & 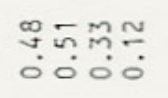 & $\stackrel{\infty}{\dddot{0}} \stackrel{n}{\circ}$. & $\stackrel{\leftrightarrow}{\circ} \cdot \stackrel{m}{\circ}$ & M웅 & & $\stackrel{\bar{\sim}}{\sim}$ & \\
\hline $\begin{array}{l}\frac{\pi}{n} \\
\Delta\end{array}$ & & 은으 & $\begin{array}{l}\text { mo } \\
0 \\
0 \\
0\end{array}$ & $\cdots$ & $\cdots$ & $\cdots$ & & $\cong$ & \\
\hline $\begin{array}{l}\underset{\widetilde{U}}{\Psi} \\
\underset{\alpha}{\Psi}\end{array}$ & & 임 & 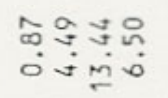 & 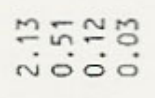 & $\stackrel{M}{\circ} \cdot \stackrel{\circ}{\circ} \cdot \stackrel{\circ}{\circ}$ & 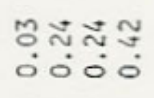 & & $\begin{array}{l}a \\
\dot{a}\end{array}$ & \\
\hline 总 & & $\circ \infty$ & 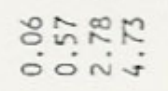 & 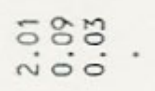 & $\ldots$ & $\begin{array}{l}0 \% \\
\circ 0 \\
0\end{array}$ & & $\stackrel{\sim}{:}$ & \\
\hline 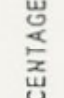 & & 요 & $\cdots \frac{\infty}{0}$ & $\stackrel{0}{\circ} .$. & $\cdots$ & $\cdots$ & & $\stackrel{\sim}{\dddot{0}}$ & 气 \\
\hline 总 & & $\therefore 0$ & $\begin{array}{l}\widetilde{m}=a \\
00=m\end{array}$ & 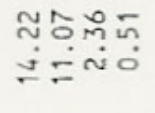 & $\begin{array}{l}\text { momm } \\
\text { óñó }\end{array}$ & 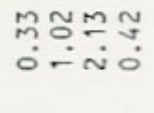 & & $\stackrel{\sim}{\infty}$ & 总 \\
\hline & $\stackrel{n}{x}$ & & & & & & $\begin{array}{l}9 \\
0\end{array}$ & o & 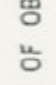 \\
\hline - & $\frac{\overrightarrow{2}}{\vec{J}}$ & $\frac{\frac{\delta}{\alpha}}{a}$ & 쏧 & w $\underset{w}{w} \underset{w}{w} 心$ & 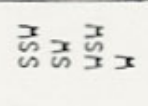 & 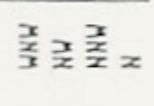 & 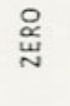 & 홍 & $\begin{array}{l}\text { 飶 } \\
\text { 罢 } \\
\end{array}$ \\
\hline
\end{tabular}




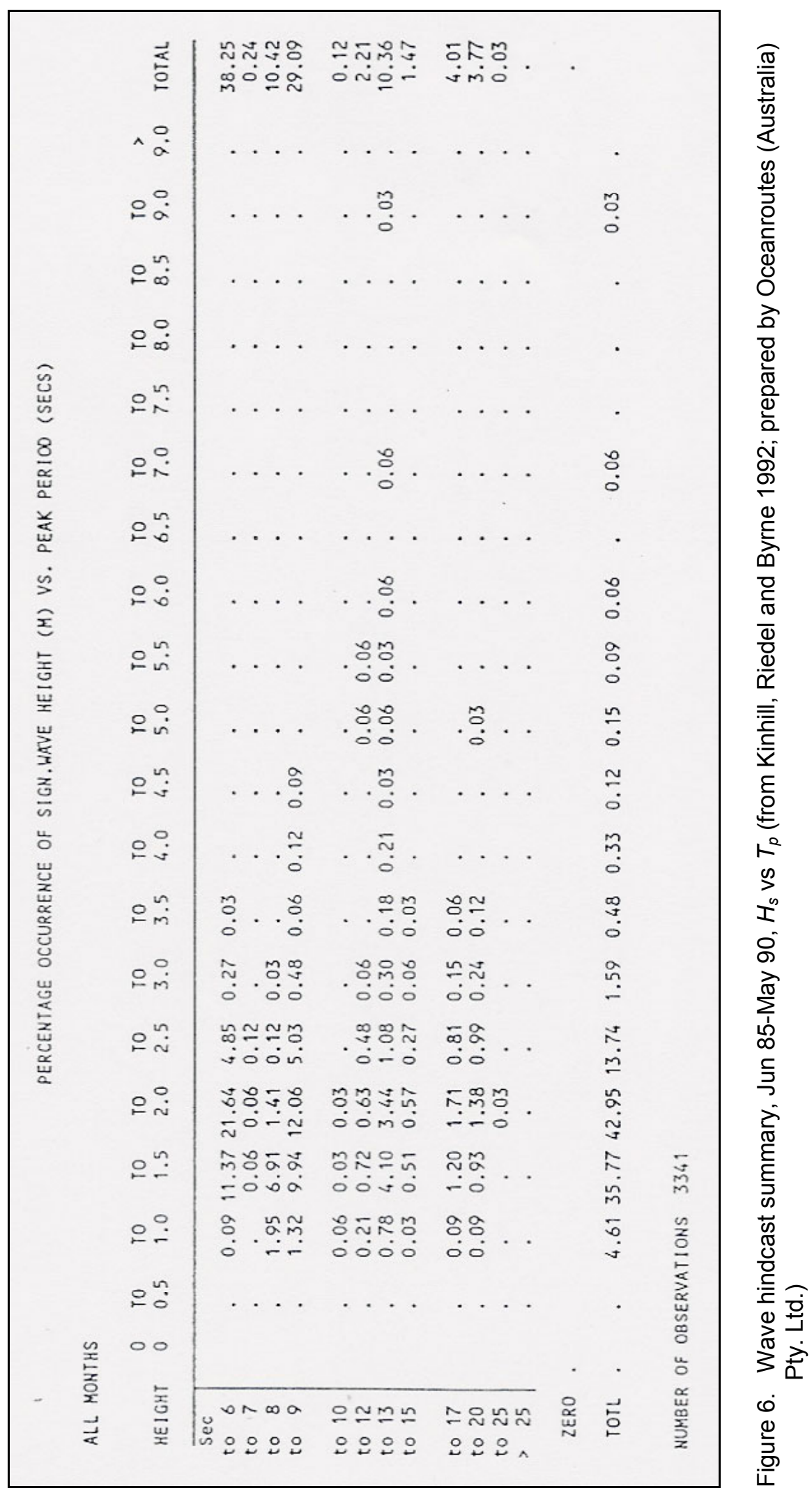




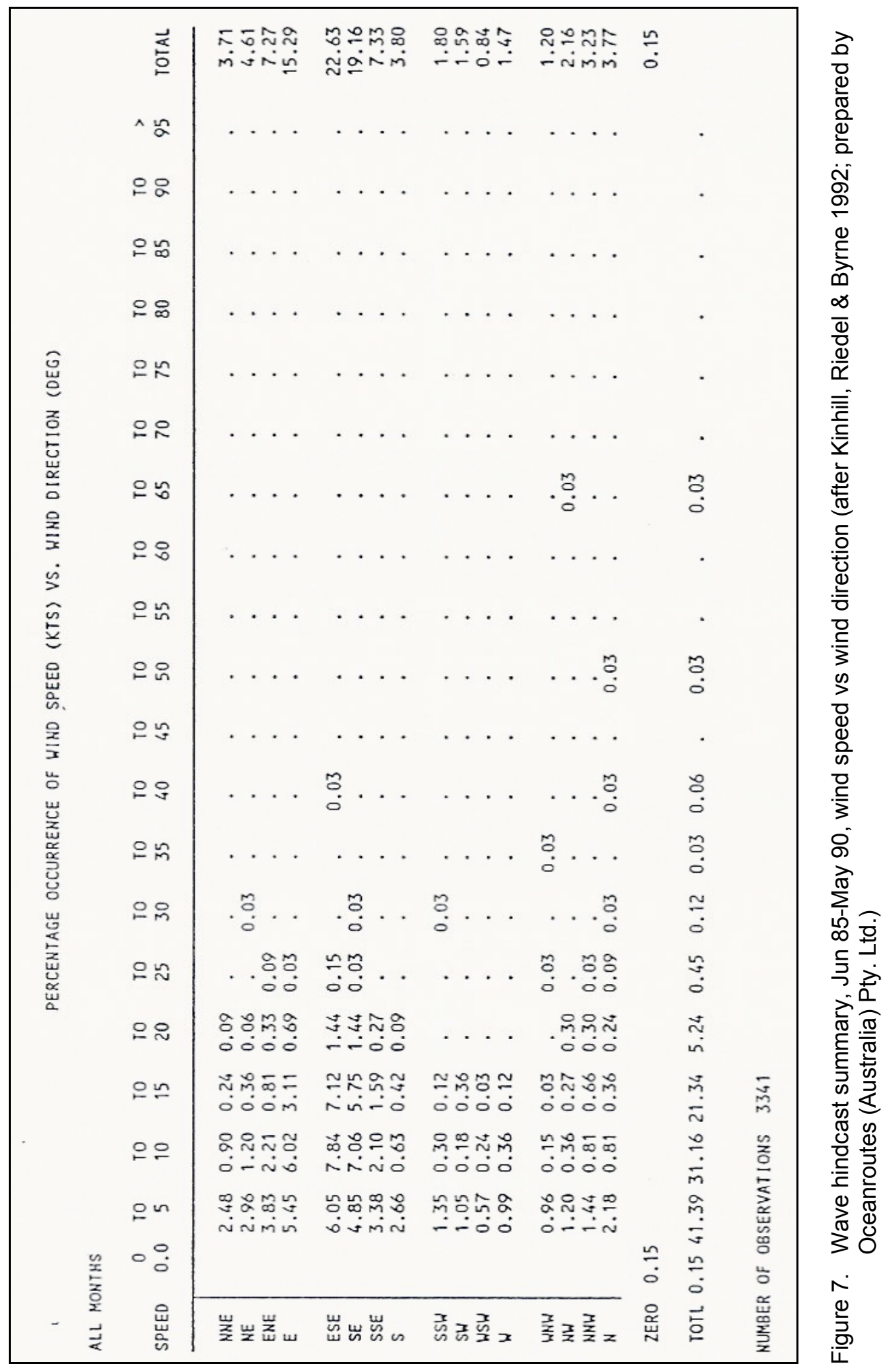




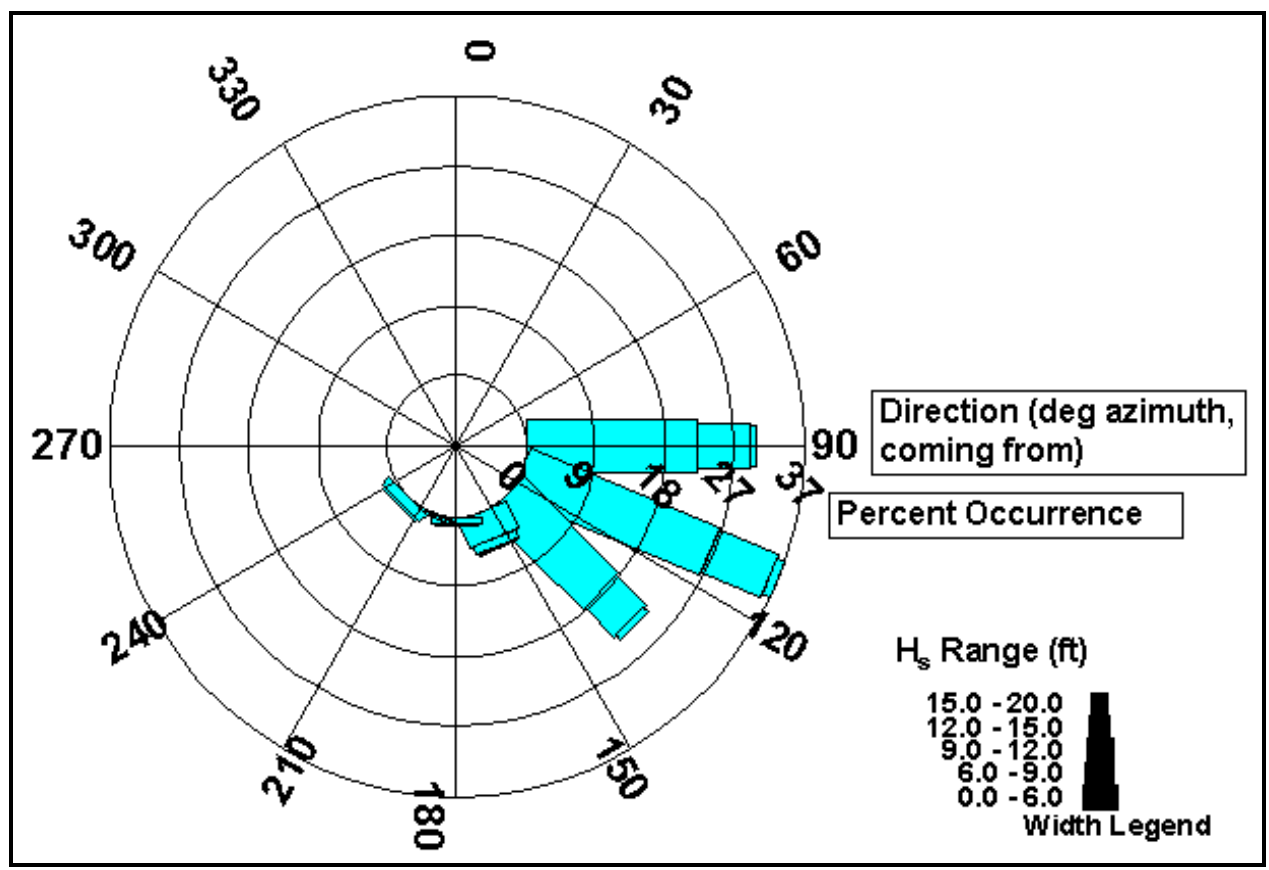

Figure 8. Wave height rose, deepwater hindcast, Jun 85-May 90 (To convert feet to meters, multiply by 0.3048 )

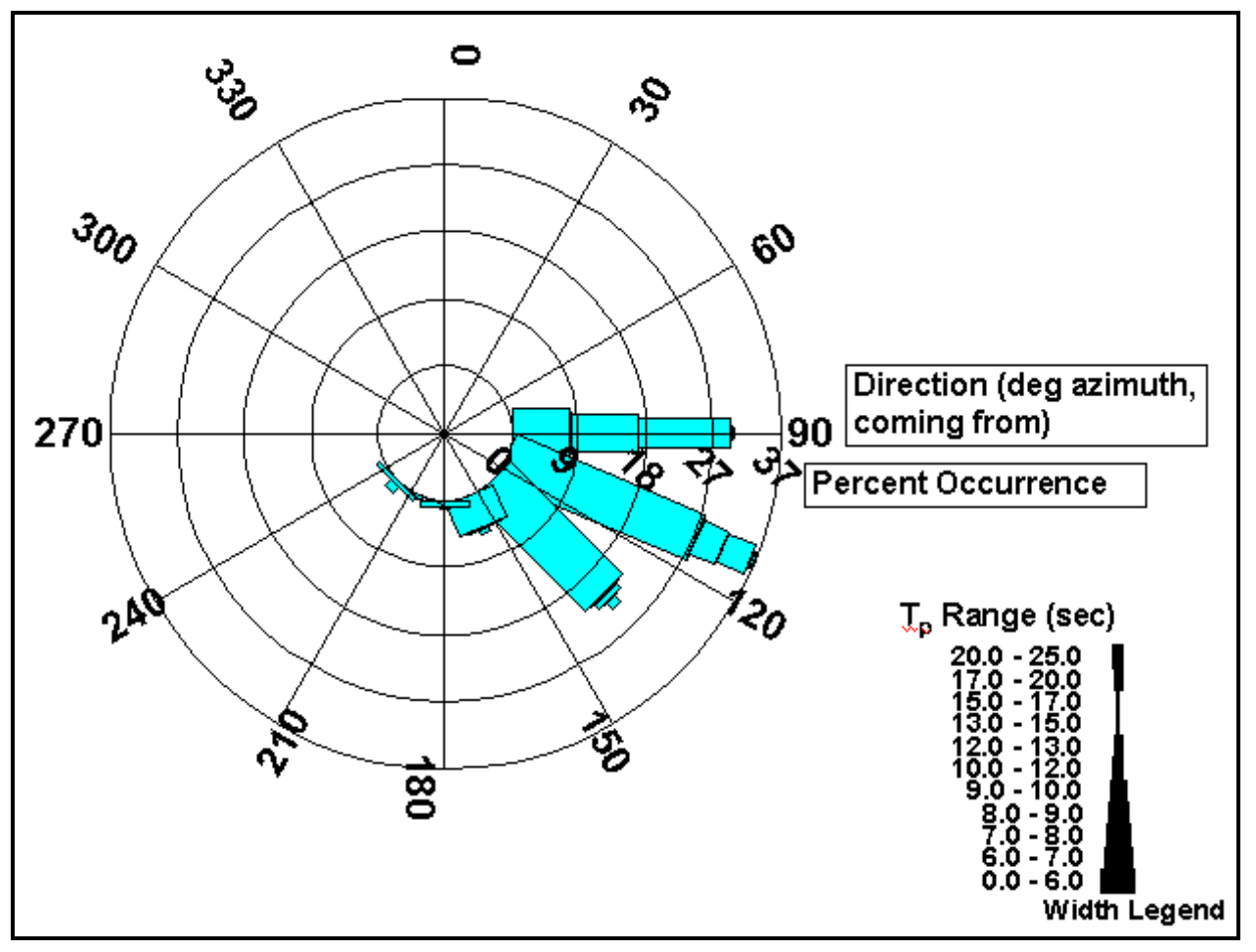

Figure 9. Wave period rose, deepwater hindcast, Jun 85-May 90 


\section{Numerical Model}

\section{Objectives and Approach}

The numerical model studies had two main objectives:

a. Develop the numerical model application to adequately represent study areas.

$b$. Use the numerical model to evaluate wave response at alternative harbor sites.

The numerical model used for the studies, CGWAVE, is the standard CHL tool for numerical harbor wave investigations. The model includes the following assumptions:

a. No wave transmission through breakwaters.

$b$. No wave overtopping of structures.

c. No testing or optimized structure crest elevations above the water surface.

d. No evaluation of currents.

$e$. Diffraction around structure ends is represented by diffraction around a blunt vertical wall with specified reflection coefficient.

Most of the limitations imposed by these assumptions are not a concern for the present study. CGWAVE is considered suitable for meeting the numerical modeling objectives of the Pago Pago Harbor wave response study.

The harbor wave response model is described in the following section, including a general description of the CGWAVE model and implementation of the model for the Pago Pago Harbor study. The final section of this chapter describes the test procedures and calculations.

As part of the test procedures, a suite of incident wave conditions must be specified at the seaward boundary of the area covered by CGWAVE. Incident short waves are determined by consideration of the hindcast wave climate outside the harbor. Incident long waves are specified over a broad range of frequencies, 
but only a normal incident direction identifies possible long-period resonant responses.

Four alternative harbor sites were studied. Results for wind waves and swell are presented in Chapter 4. Long-period oscillation results are presented in Chapter 5. The presentation focuses on wave conditions in the vicinity of proposed dock facilities, but some results over the full model area are also given.

\section{Model Description}

\section{Model formulation}

The numerical wave model CGWAVE is a steady state finite element model used in the calculation of wave response in harbors of varying size and depth. It may also be applied along open coastal regions, at coastal inlets, around islands, and around fixed or floating structures. CGWAVE simulates the combined effects of wave refraction and diffraction included in the extended mild-slope equation, also known as the steep-slope equation. It can also include effects of wave dissipation by friction, breaking, nonlinear amplitude dispersion, and harbor entrance losses. The basic model deals with regular waves, but irregular (spectral) wave conditions can be simulated by combining regular wave results.

Several fundamental theoretical and computational advances are included in the model. The open boundary condition (seaward boundary of the model domain) is treated with a new parabolic approximation method along with the classical super-element technique. An efficient iterative procedure (conjugate gradient method) is used to solve the discretized model equations, enabling the model to be used practically for larger domains.

The CGWAVE model is interfaced with commercially available Corps of Engineers-supported software to assist in preparing model grids and other inputs and in displaying model results. This software-assisted pre- and postprocessing is needed in any practical application.

More information on CGWAVE is available from Demirbilek and Panchang (1998) and from the model internet web site (http://chl.wes.army.mil/research/ wave/wavesprg/numeric/wentrances/cgwave.htp). The software package for preand postprocessing is part of the Surface Water Modeling System (SMS). The SMS software is also described through the model web site.

\section{Finite element grids}

Bathymetric data for Tutuila are available on National Oceanic and Atmospheric Administration (NOAA), National Ocean Service (NOS) hydrographic chart 83484. In addition, the U.S. Army Engineer District, Honolulu (HED), provided detailed bathymetric contours from a recent hydrographic survey of the entire Pago Pago Harbor embayment. Bathymetry 
for the numerical model was obtained by using HED data and supplementing with NOS chart data in areas seaward of HED coverage.

The numerical model seaward boundary is a semicircle. For this study, the model boundary was extended seaward far enough to encompass relevant shallow areas outside the entrance to Pago Pago Harbor embayment (Figure 10). The model domain includes Taema Bank and extends beyond to deep water.

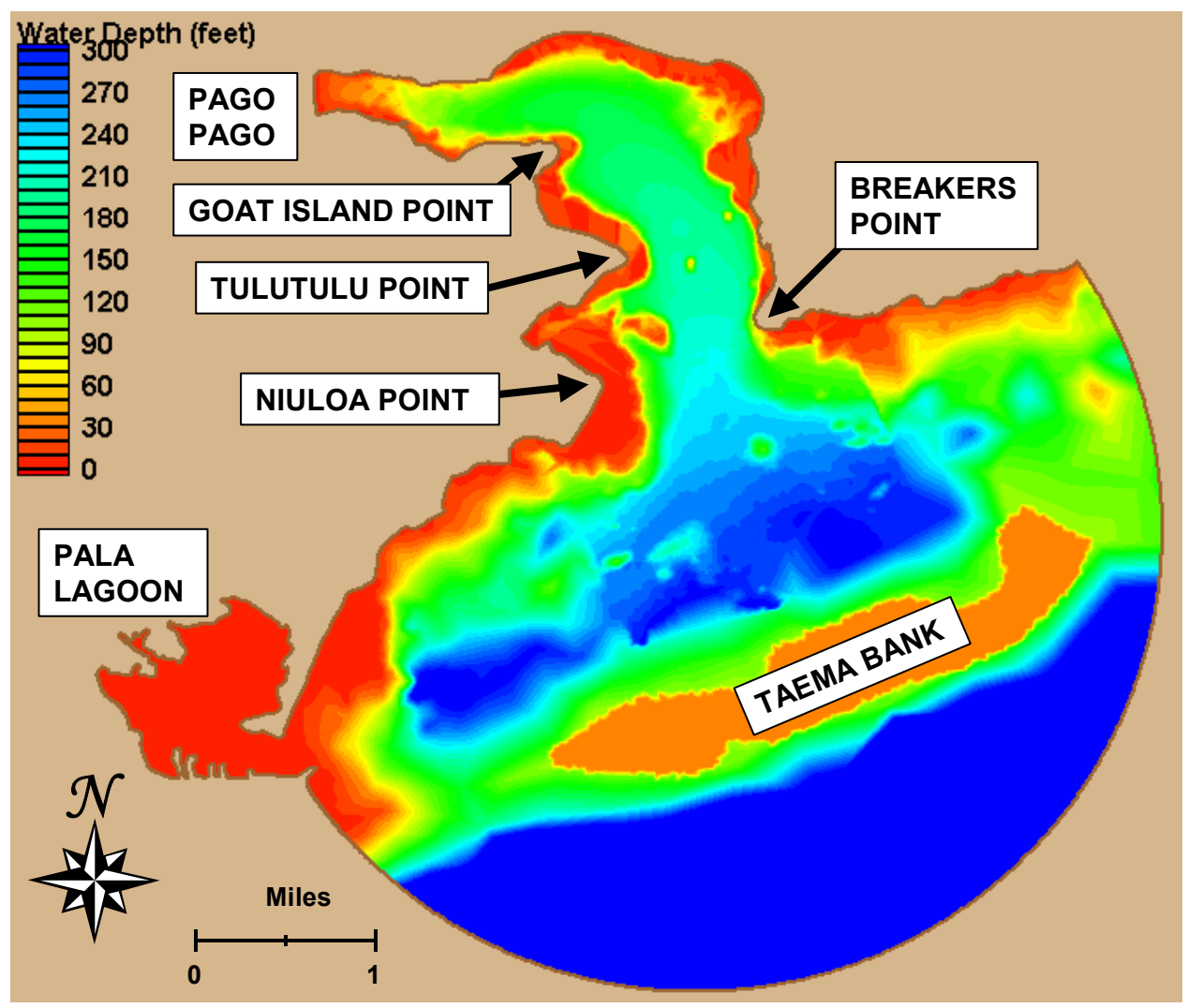

Figure 10. Model bathymetry, existing harbor (To convert to SI, multiply feet by 0.3048 for meters; multiply miles by 1.609347 for kilometers)

A finite element grid was constructed over the model domain (Figure 11). Grid element size is based on the needed model resolution for the shortest period waves in the shallowest water depth of concern in the study. For the longer period waves, the grid gives a high degree of resolution. Grid characteristics are summarized in Table 2. Bathymetric data discussed above were transferred onto the finite element grid. The SMS software was used for all bathymetry and grid development.

Reflection coefficients, $K_{r}$, are needed for all solid boundaries. For wind wave and swell tests, $K_{r}$ values were estimated as zero in consideration of the pervasive coral reefs fringing the shoreline. Bottom friction was set to zero. Additional parameter values used in the numerical model are summarized in Table 3. 


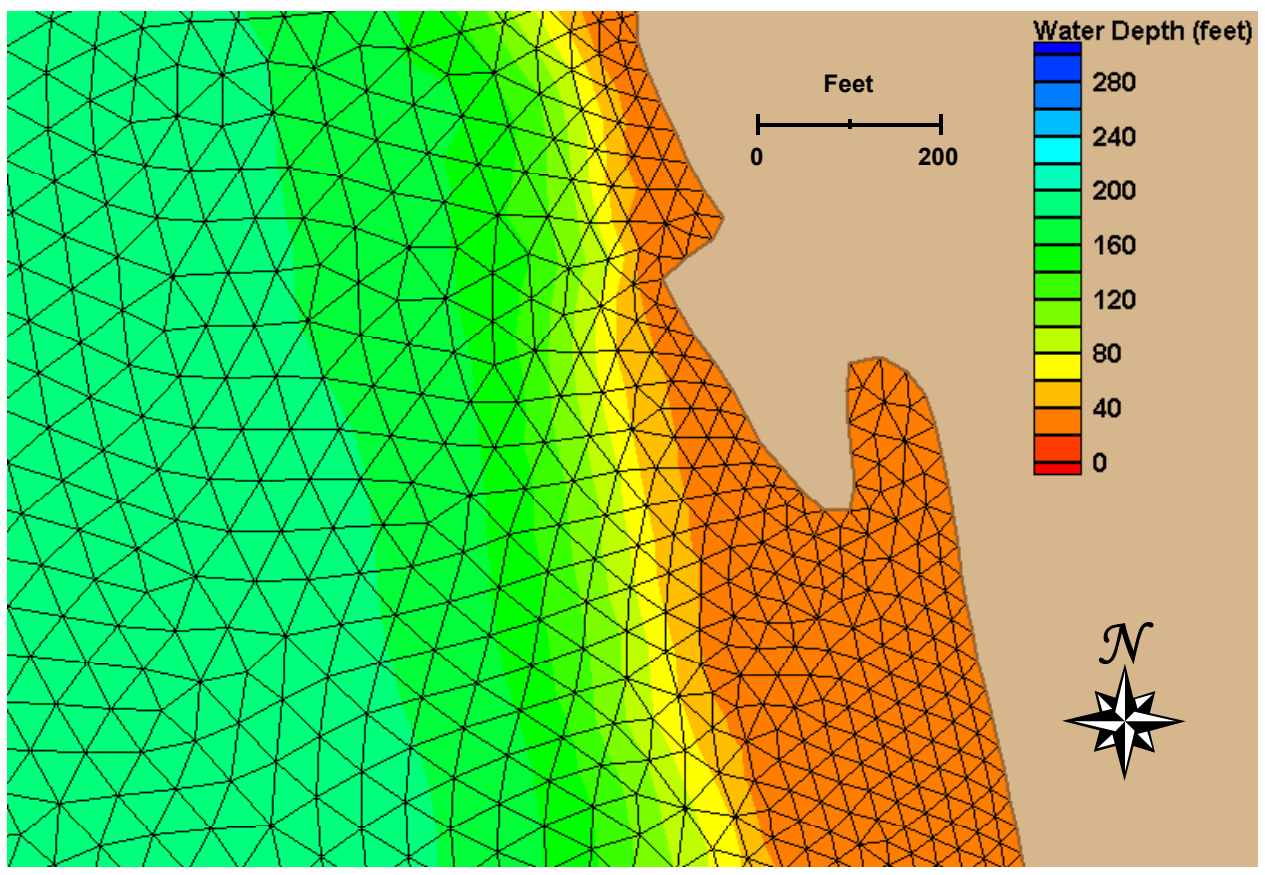

Figure 11. Illustration of model grid, Anasosopo site (To convert feet to meters, multiply by 0.3048 )

\begin{tabular}{|c|c|c|c|c|}
\hline \multicolumn{5}{|c|}{$\begin{array}{l}\text { Table } 2 \\
\text { Grid Size }\end{array}$} \\
\hline $\begin{array}{l}\text { Harbor } \\
\text { Plan }\end{array}$ & Elements & Nodes & $\begin{array}{l}\text { Semicircle Boundary } \\
\text { Nodes }\end{array}$ & $\begin{array}{l}\text { Range of Distance Between } \\
\text { Adjacent Nodes (ft) }\end{array}$ \\
\hline$\overline{\text { Existing }}$ & \begin{tabular}{c|}
588,329 \\
\end{tabular} & 29296,932 & $\overline{7726}$ & 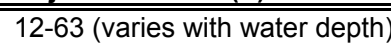 \\
\hline
\end{tabular}

\begin{tabular}{|c|c|c|}
\hline \multirow[b]{2}{*}{ Parameter } & \multicolumn{2}{|c|}{ Value } \\
\hline & $\begin{array}{l}\text { Short } \\
\text { Waves }\end{array}$ & $\begin{array}{l}\text { Long } \\
\text { Waves }\end{array}$ \\
\hline Number of terms in series & 35 & 35 \\
\hline Number of iterations for checking convergence & 1 & 1 \\
\hline Maximum number of iterations & 500,000 & 500,000 \\
\hline Maximum number of iterations for nonlinear mechanisms & 25 & 8 \\
\hline Bottom friction & 0.00 & 0.02 \\
\hline Wave breaking & off & off \\
\hline Nonlinear dispersion & off & off \\
\hline Exterior reflection (shore boundaries outside grid domain) & 0.0 & 1.0 \\
\hline Tolerance for equations & $10^{-9}$ & $10^{-9}$ \\
\hline Tolerance for nonlinear mechanisms & $10^{-4}$ & $10^{-4}$ \\
\hline $\begin{array}{l}\text { Semicircle orthogonal orientation, deg counterclockwise from }+x \text { axis } \\
(0=\text { east, } 90=\text { north, } 180=\text { west, } 270=\text { south })\end{array}$ & 305.2 & 305.2 \\
\hline
\end{tabular}


Different parameters are used for the long wave tests. The reflection coefficient was set to 1.0 for all boundaries, since long waves generally reflect very well from a coastal boundary. Long waves are more affected by bottom friction than short waves, so a value greater than zero is appropriate. The value is best determined by calibration with field data when possible. Since no field data are available in this area, a value of 0.02 was selected, based on previous calibration at Kahului Harbor, Maui, Hawaii (Thompson and Demirbilek in preparation). These and other parameters are summarized in Table 3.

\section{Test Procedures and Calculations}

\section{Incident wave conditions}

A range of short- and longwave conditions incident to the Pago Pago Harbor embayment was considered. A representative range of wave periods and directions which could cause damaging waves inside the harbor was included, based on the hindcast wave climate and buoy data.

The shortwave periods and approach directions considered are given in Table 4. The range of wave periods shown was tested for each direction shown. These conditions provide reasonable coverage of the wave climate. Directions were chosen to cover the full directional exposure of the harbor entrance, in 22.5-deg increments (Figure 12). These incident wave components can be expected to give a good representation of the directional spectrum in postprocessing.

\begin{tabular}{|c|c|}
\hline \multicolumn{2}{|c|}{$\begin{array}{l}\text { Table } 4 \\
\text { Summary of Incident Shortwave Conditions }\end{array}$} \\
\hline Wave Period (sec) & Wave Direction (deg az., coming from) \\
\hline 26 & 90.0 \\
\hline 8 & 112.5 \\
\hline 10 & 135.0 \\
\hline 12 & 157.5 \\
\hline & 180.0 \\
\hline & 202.5 \\
\hline & 225.0 \\
\hline
\end{tabular}

For the study of alternative harbor sites, CGWAVE was run with shortwave periods of 6 to $12 \mathrm{sec}$ and the full set of directions in all possible combinations. Wave heights of 1.5, 2.5, 3.5, 5, and $7 \mathrm{~m}(4.9,8.2,11.5,16.4$, and $23.0 \mathrm{ft})$ were run for each period/direction combination. Model results were then properly weighted and recombined to represent a directional spectrum for each bin in the 5 -year incident wave climate summary. Selected longer-period cases (14 to $20 \mathrm{sec}$ ) were run with a single wave height of $2 \mathrm{~m}$ and direction of east southeast. The longest period represents a very long swell condition. These cases, which are outside the normal wave climate, were run in the event some special concerns related to long period swell should need to be addressed in the future. 


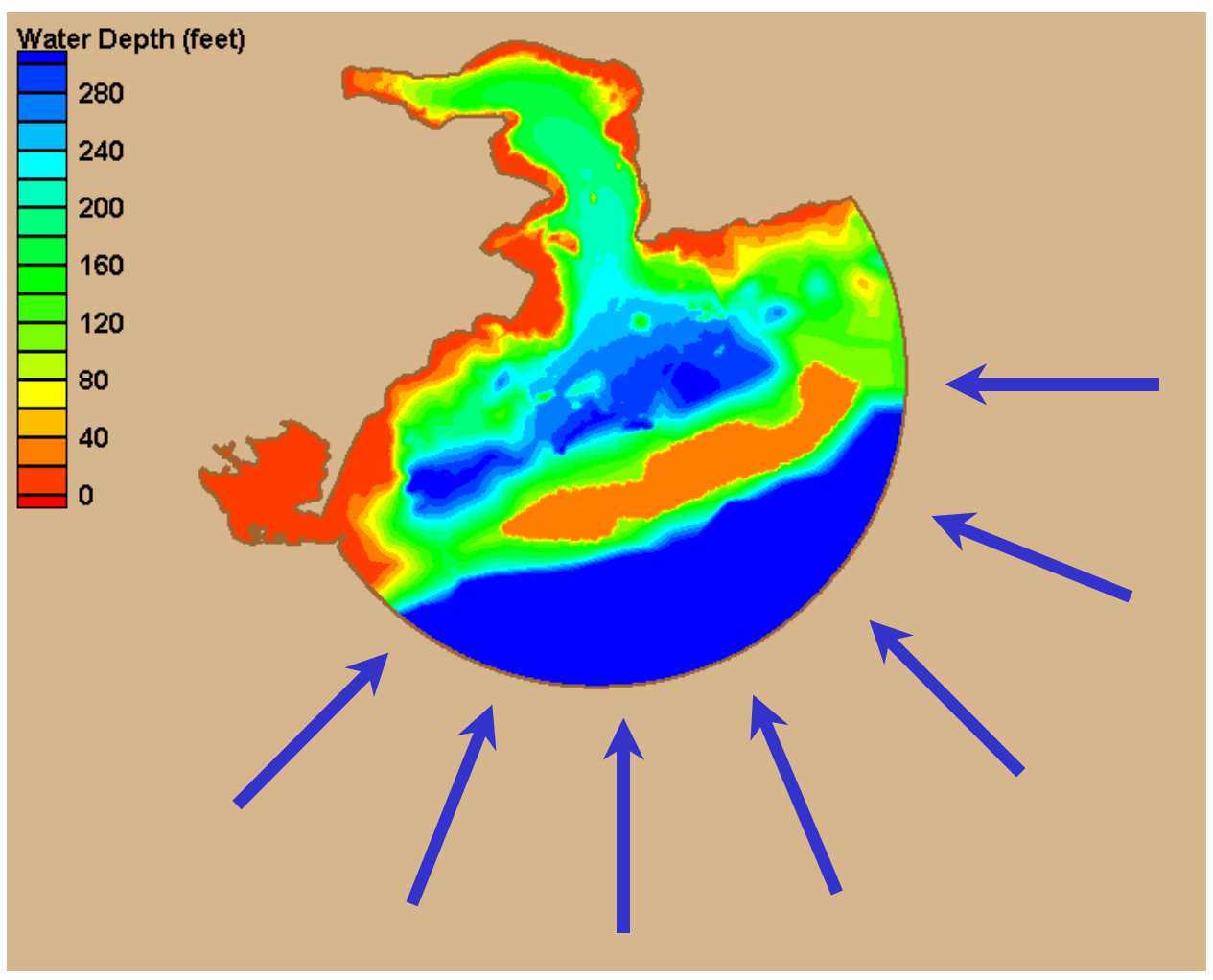

Figure 12. Incident shortwave directions modeled (To convert feet to meters, multiply by 0.3048 )

A hypothetical time-history of wind waves and swell was reconstructed to represent the wave climate. The time-history contained 10,000 observations, so the number of observations in each $T_{p}$ and $\theta_{p}$ bin is the percent occurrence for that bin multiplied by 100 . Values of $H_{s}$ were assigned to each observation to properly represent statistics of $H_{s}$ and $T_{p}$ bins. The specific $H_{s}$ values were randomly varied over the bin range. With this hypothetical time-history, procedures used in previous studies where actual time-histories of incident waves were available could be applied to analyze waves at any point in the model domain.

Incident longwave conditions considered are given in Table 5. Previous harbor resonance studies have helped to define a standard range of longwave periods over which resonance may occur and a frequency resolution fine enough to reveal any significant resonant conditions. Based on that experience, a fine resolution in wave frequency was used in this study over the full range of possible resonant conditions (25- to 1,000 -sec periods) to ensure that all important peaks were identified. A total of 468 periods was considered, as in previous studies. Only one approach direction is included, since past studies have indicated that harbor response is relatively insensitive to incident longwave direction. This direction, 144.8 deg azimuth, represents a wave coming from the midpoint of the semicircular boundary and approaching the harbor entrance from deep water. 


\begin{tabular}{|c|c|}
\hline \multicolumn{2}{|c|}{$\begin{array}{l}\text { Table } 5 \\
\text { Summary of Incident Longwave Conditions }\end{array}$} \\
\hline Wave Period(sec) & Wave Direction (deg az., coming from) \\
\hline 25.00 & 144.8 \\
\hline 25.06 & 144.8 \\
\hline 25.13 & 144.8 \\
\hline$\ldots{ }^{1}$ & 144.8 \\
\hline $1,000.0$ & 144.8 \\
\hline
\end{tabular}

One water level was tested. The tide range at Tutuila is relatively small, with a mean range of $0.76 \mathrm{~m}(2.5 \mathrm{ft})$. Harbor wave response is unlikely to vary much with water level over this tidal range. The water level was selected as mean low water, the reference datum for bathymetric data.

\section{Calculation of spectra}

Numerical model test results for short waves in Pago Pago Harbor embayment are all based on spectral postprocessing of the initial CGWAVE runs. For the parameter settings used in short wave runs (Table 3), incident wave height had no significant impact on amplification factors at study sites. Hence, short-wave amplification factors are all computed in the form of $\left(A_{\text {amp }}\right)_{\text {eff }}$ as described by Thompson et al. (1996). This approach requires, first, that CGWAVE be run with the range of wave periods and directions to be considered in the spectral calculations. Second, for each value of peak wave period, $T_{p}$, and wave approach direction, $\theta_{p}$; a spectral peak enhancement factor, $\gamma$; and directional spreading factor, $s$, must be specified. The $T_{p}$ and $\theta_{p}$ values were taken to represent bins in the 5-year hindcast summaries. Values for $\gamma$ and $s$ were approximated by the same procedure developed in the previous study. This procedure has been further tested and become a standard approach in CHL spectral wave model studies (Smith, Sherlock, and Resio 2001).

\section{Output locations}

In order to obtain special coverage of areas where harbor operations would most likely be affected by wave conditions, output lines were selected to cover mooring areas along all proposed alternative harbor areas (Figure 13). The saving sequence began with the south end of the line at the Anasosopo site and proceeded counter clockwise into the embayment, as indicated in the figure. Model results were saved at regular intervals along each line, with interval width ranging from $15.1 \mathrm{~m}(50 \mathrm{ft})$ to $39.1 \mathrm{~m}(128 \mathrm{ft})$. 


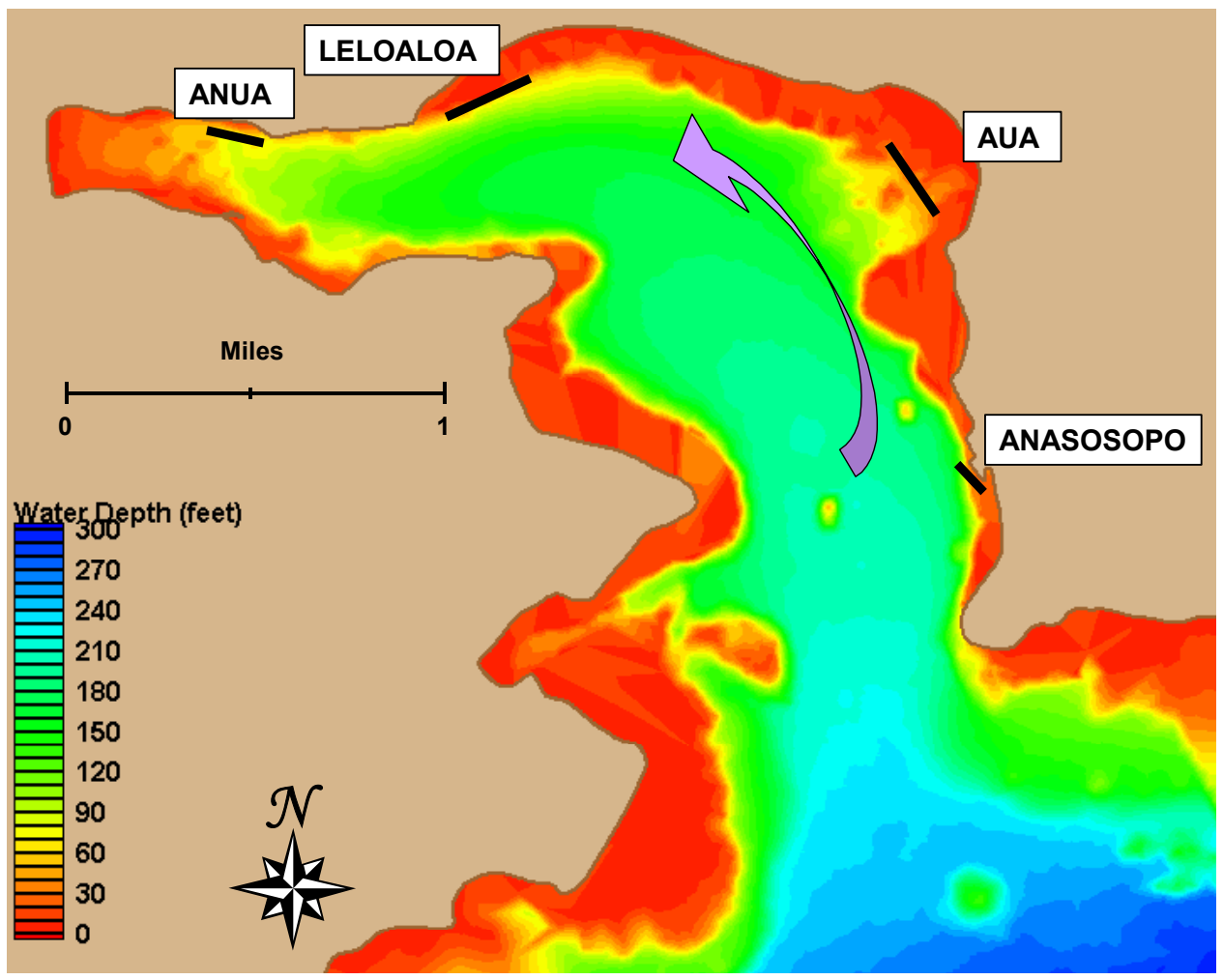

Figure 13. Model output lines (To convert feet to meters, multiply by 0.3048 ) 


\section{Harbor Response to Wind Waves and Swell}

Numerical model studies of the harbor response to wind waves and swell were directed primarily toward assessing the operational performance of alternative harbor sites and establishing design wave and water levels. Results are summarized in this chapter. Amplification factors are discussed in the following section. The next section gives $H_{s}$ values exceeded 10 percent of the time, a result more directly applicable to operational performance, and values exceeded 1 percent of the time, an indicator of more extreme conditions. The $H_{s}$ values are derived from a combination of amplification factors from the numerical model and wave hindcast information outside the harbor. They are compared to operational criteria for wind waves and swell. The final section gives extreme wave and water level information for design.

\section{Amplification Factors}

Each CGWAVE model run produces wave height results over the model domain. Results were saved along output lines representing the four alternative harbor sites, as discussed in Chapter 3. Wave height results were converted to amplification factor results, where amplification factor is defined as the ratio of local wave height to incident wave height. Amplification factors from the various CGWAVE runs are then weighted and combined to represent directionally spread shortwave spectra in the form of $\left(A_{\text {amp }}\right)_{\text {eff }}$ for the variety of wind wave and swell conditions in the 5-year hindcast summary.

Amplification factors from the CGWAVE runs, before computation of $\left(A_{\text {amp }}\right)_{\text {eff }}$, can be somewhat variable because of the discrete values of wave period and direction being modeled in each run. However, they are the basis for the directional spectral calculations, and they can illustrate some basic characteristics of wind wave and swell response at the study sites. Amplification factors for each wave direction, with values for the various wave periods $(6,8,10$, and $12 \mathrm{sec}$ ) averaged together, Figure 14. They illustrate the impact of incident wave direction on amplification factor at the study sites. Points shown in the figure begin with the southernmost point on the Anasosopo output line and proceed north and counterclockwise, as illustrated in Figure 13. At Anasosopo, waves from the south have heights about 0.6 times the incident wave height. At Aua, waves from the south also have the biggest impact. At Leloaloa, waves from 


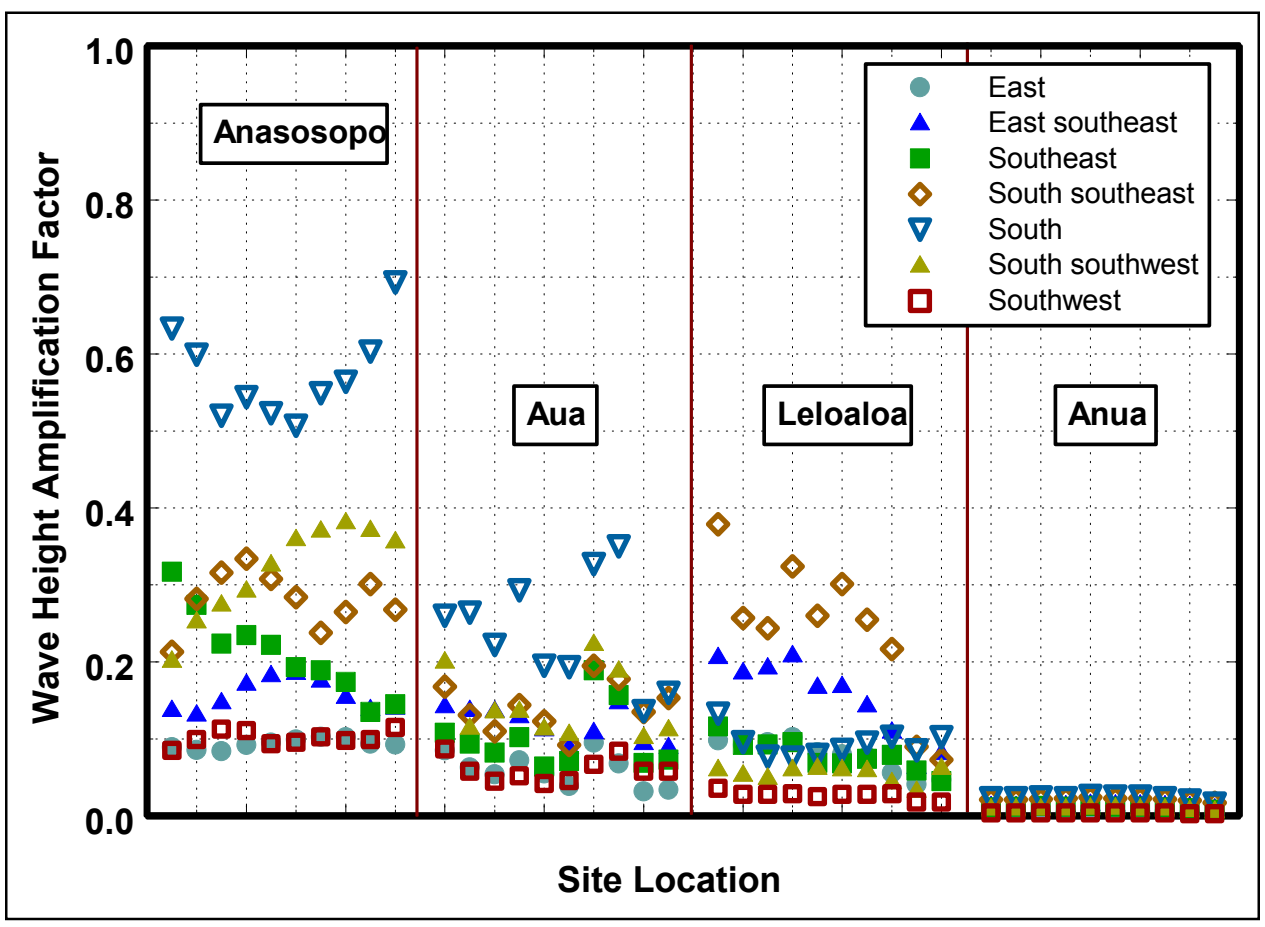

Figure 14. Wave height amplification factor, average for 6- to 12-sec wave periods

south southeast have the biggest impact. Amplification factors are near zero at the highly sheltered Anua site. Bathymetry in the immediate area of the study site can have a localized effect on amplification factor. For example, there is a small, shallow hump just seaward of the output line at Aua which affects several output points.

Although waves from the south at Anasosopo produce the highest amplification factors, the hindcast wave climate shows that waves from this direction rarely occur. To illustrate amplification factors which incorporate wave climate information, a climatological average amplification factor was computed at each output point by weighting each CGWAVE result by an appropriate percent occurrence in the hindcast climate (Figure 15). Although these results still do not represent directionally spread spectra, they provide a more realistic perspective on how much incident wave energy is diminished at the study sites. These results show that all of the sites have considerable protection from the incident wave climate. Anasosopo is the most exposed site, but differences between sites (other than highly protected Anua) are relatively small.

\section{Evaluation against Operational Criteria for Wind Waves and Swell}

Standard operational criteria used by the U.S. Army Corps of Engineers (USACE) for wind waves and swell in shallow draft harbors are: 


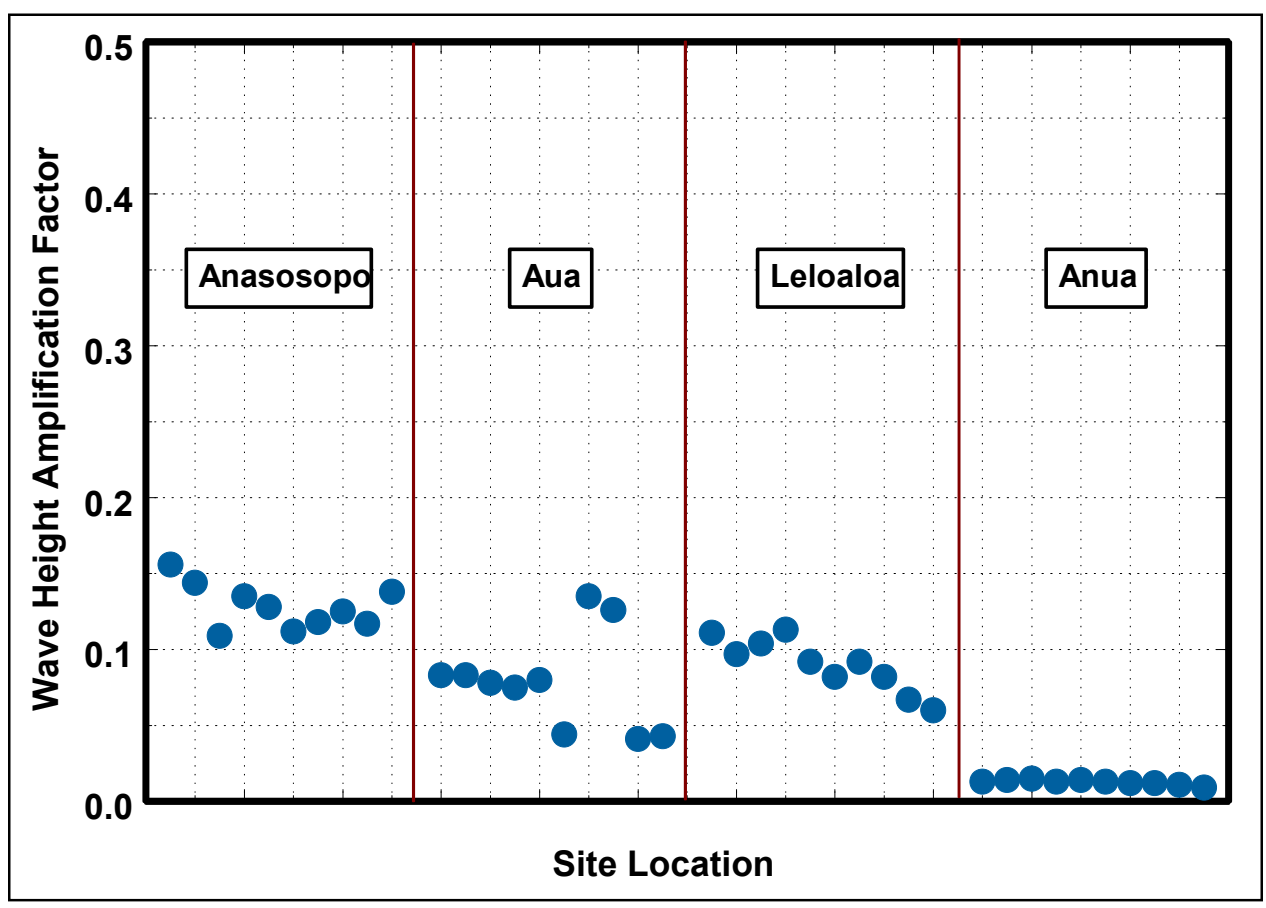

Figure 15. Wave height amplification factor based on incident wave climate

a. Wave height in berthing areas will not exceed $0.3 \mathrm{~m}(1 \mathrm{ft})$ more than 10 percent of the time.

$b$. Wave height in entrance and access channels and turning basins will not exceed $0.6 \mathrm{~m}(2 \mathrm{ft})$ more than 10 percent of the time.

Standard criteria for wind waves and swell in deep draft harbors, such as Pago Pago Harbor, are not so well established and are more dependent on vessel size, mooring configuration, and wave period. However, the criteria for shallow draft harbors can provide a useful basis for comparing alternative sites at Tutuila. The $0.3-\mathrm{m}(1-\mathrm{ft})$ criterion has applicability to small moored vessels. Larger deepdraft vessels are typically more tolerant of waves, and the $0.6-\mathrm{m}(2-\mathrm{ft})$ criterion provides a more relaxed metric for operational suitability of potential dock areas. However, some deep-draft operations can be quite sensitive to wave motions. Experience with the Alaska ferry system (vessel lengths up to $90 \mathrm{~m}(300 \mathrm{ft})$ ) suggests that the USACE $0.3-\mathrm{m}$ (1- $\mathrm{ft}$ ) criterion in berthing areas is a meaningful threshold for that application (personal communication from Harvey Smith, Department of Transportation and Public Facilities, State of Alaska, 2002).

Another, perhaps more valuable criterion for evaluating proposed new pier areas is to compare with the existing piers. Many years of practical experience can then be approximately transferred to new site considerations.

Wave heights for assessing the USACE criteria were computed by combining the incident wave time-history developed to represent the hindcast wave information with numerical model results to create a time-history of wave heights along 
each output line. For each recreated observation, the corresponding wave height at a harbor point is:

$$
\left(H_{s}\right)_{\text {harbor }}=\left(A_{\text {amp }}\right)_{\text {eff }} \times\left(H_{s}\right)_{\text {incident }}
$$

where

$$
\begin{aligned}
\left(H_{s}\right)_{\text {harbor }}= & \text { significant wave height at a point in the harbor } \\
\left(A_{\text {amp }}\right)_{\text {eff }}= & \text { spectral amplification factor calculated from model results for } \\
& \text { the periods and directions in Table } 4 \text { to represent } T_{p} \text { and } \theta_{p} \text { in } \\
& \text { the incident wave time-history } \\
\left(H_{s}\right)_{\text {incident }}= & \text { incident deepwater significant wave height }
\end{aligned}
$$

The time-history of $\left(H_{s}\right)_{\text {harbor }}$ at each point along the output lines was sorted into descending order, and the value of $H_{s}$ which was exceeded 10 percent of the time, $H_{10}$, was identified. The $H_{s}$ value which was exceeded 1 percent of the time, $H_{l}$, was also identified. The $H_{s}$ with 1-percent exceedance relates to a more demanding operational condition which may be relevant to heavily used commercial docks.

Along the alternative harbor sites considered, $H_{10}$ values are between $0.15 \mathrm{~m}$ $(0.5 \mathrm{ft})$ and $0.6 \mathrm{~m}(2.0 \mathrm{ft})$, except for a value of $0.64 \mathrm{~m}(2.1 \mathrm{ft})$ at the most exposed point at Anasosopo and very low values at Anua (Figure 16 and Table 6). Points shown in the figure begin with the southernmost point on the Anasosopo output line and proceed north and counterclockwise, as illustrated in Figure 13. The highest values of $H_{10}$ occur at Anasosopo, which is the site nearest the embayment entrance and most exposed to incident waves. At Anasosopo, $H_{10}$ ranges from 0.5 to $0.6 \mathrm{~m}(1.5 \mathrm{ft}$ to $2.1 \mathrm{ft})$. These values are significantly reduced from the offshore incident wave heights, mainly because of considerable sheltering of the site by Breakers Point.

At Aua, $H_{10}$ drops to the range of 0.2 to $0.3 \mathrm{~m}(0.5 \mathrm{ft}$ to $1.0 \mathrm{ft})$, except for two higher points affected by a local bathymetric hump discussed previously. Aua is significantly more sheltered than Anasosopo. It lies deeper into the Pago Pago Harbor embayment. Breakers Point, Niuloa Point, and Tulutulu Point all afford sheltering to the Aua site. In addition, a large lobe in the fringing reef just south of the site adds to the local sheltering.

The Leloaloa site, although deeper into the embayment than Aua, is less protected from incident waves. The Leloaloa site has a more direct exposure to the commonly occurring waves from southeast directions. Values of $H_{10}$ at Leloaloa range from 0.3 to $0.4 \mathrm{~m}(1.1 \mathrm{ft}$ to $1.4 \mathrm{ft})$ along most of the line, dropping to $0.2 \mathrm{~m}(0.5$ to $0.6 \mathrm{ft})$ at the more sheltered end of the line. The Leloaloa site benefits from sheltering by Breakers Point and Tulutulu Point. The west end of the Leloaloa line also benefits from sheltering by Goat Island Point, a major impact which also benefits existing harbor facilities further west. 


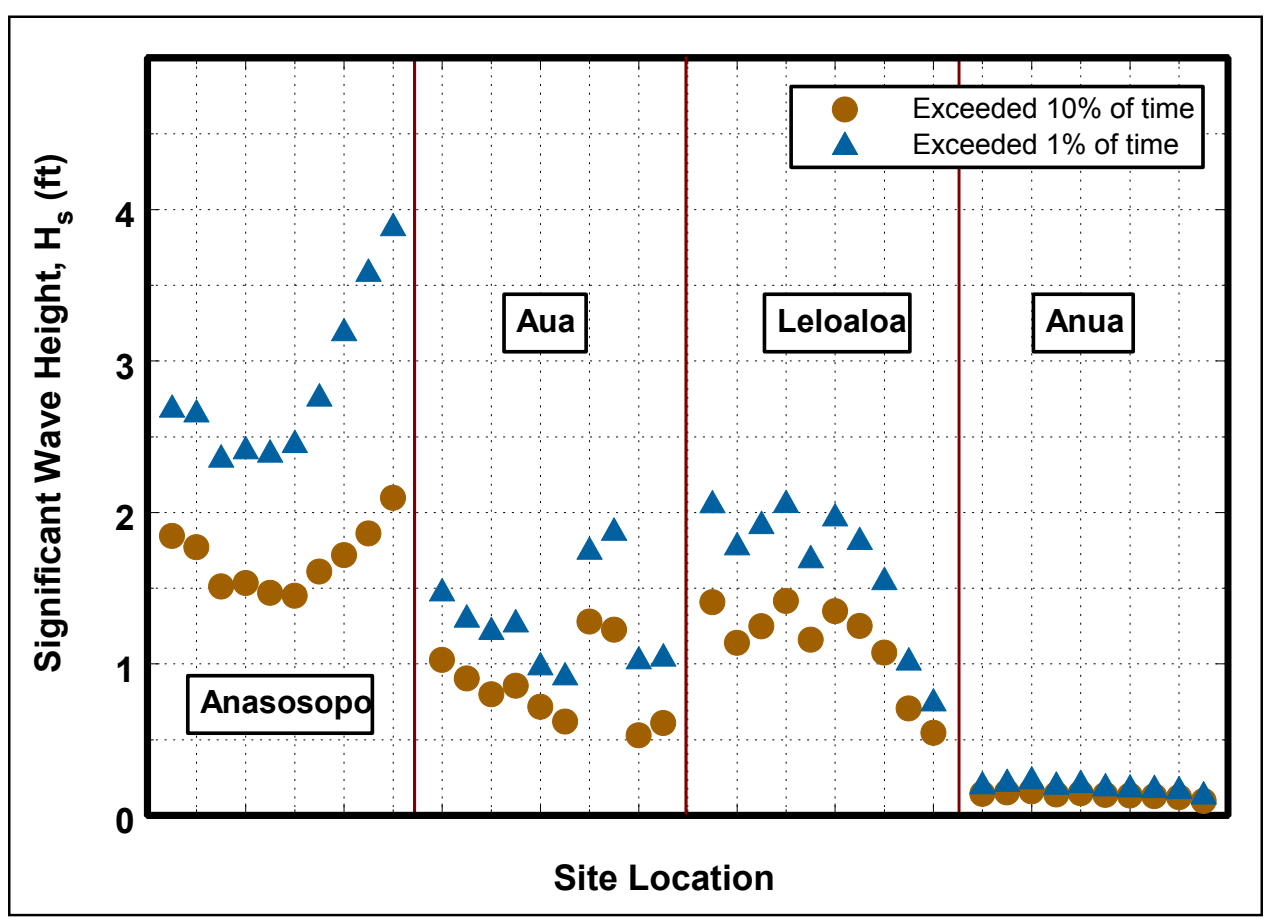

Figure 16. $H_{s}$ exceeding 10 percent and 1 percent of time at study sites (To convert feet to meters, multiply by 0.3048 )

\begin{tabular}{|c|c|c|c|c|c|c|c|c|}
\hline \multicolumn{9}{|c|}{$\begin{array}{l}\text { Table } 6 \\
H_{s} \text { Exceeding } 10 \text { Percent and } 1 \text { Percent of Time at Study Sites }\end{array}$} \\
\hline \multirow{2}{*}{$\begin{array}{l}\text { Point } \\
\text { Along } \\
\text { Line }^{1} \\
\end{array}$} & \multicolumn{2}{|c|}{ Anasosopo } & \multicolumn{2}{|c|}{ Aua } & \multicolumn{2}{|c|}{ Leloaloa } & \multicolumn{2}{|c|}{ Anua } \\
\hline & $H_{10}, \mathrm{ft}^{2}$ & $H_{1}, \mathrm{ft}^{2}$ & $H_{10}, \mathrm{ft}^{2}$ & $H_{1}, \mathrm{ft}^{2}$ & $H_{10}, \mathrm{ft}^{2}$ & $H_{1}, \mathrm{ft}^{2}$ & $H_{10}, \mathrm{ft}^{2}$ & $H_{1}, \mathrm{ft}^{2}$ \\
\hline 1 & 1.85 & 2.69 & 1.03 & 1.48 & 1.41 & 2.06 & 0.14 & 0.21 \\
\hline 2 & 1.77 & 2.66 & 0.91 & 1.31 & 1.14 & 1.79 & 0.15 & 0.22 \\
\hline 3 & 1.51 & 2.37 & 0.80 & 1.23 & 1.25 & 1.93 & 0.16 & 0.24 \\
\hline 4 & 1.53 & 2.42 & 0.86 & 1.28 & 1.42 & 2.06 & 0.14 & 0.21 \\
\hline 5 & 1.47 & 2.40 & 0.72 & 0.99 & 1.16 & 1.70 & 0.15 & 0.22 \\
\hline 6 & 1.45 & 2.46 & 0.62 & 0.93 & 1.35 & 1.98 & 0.14 & 0.20 \\
\hline 7 & 1.61 & 2.77 & 1.28 & 1.76 & 1.25 & 1.82 & 0.13 & 0.19 \\
\hline 8 & 1.72 & 3.20 & 1.23 & 1.88 & 1.08 & 1.56 & 0.13 & 0.18 \\
\hline 9 & 1.86 & 3.59 & 0.53 & 1.03 & 0.71 & 1.03 & 0.12 & 0.18 \\
\hline 10 & 2.10 & 3.89 & 0.61 & 1.05 & 0.55 & 0.76 & 0.10 & 0.14 \\
\hline
\end{tabular}

The Anua site lies deep into the embayment, with excellent natural protection from wind waves and swell. Values of $H_{10}$ range from 0.03 to $0.06 \mathrm{~m}(0.1$ to $0.2 \mathrm{ft}$ ).

Values of $H_{1}$ are higher than $H_{10}$ but show similar relative trends. Differences between $H_{1}$ and $H_{10}$ are biggest at Anasosopo. Values of $H_{l}$ range

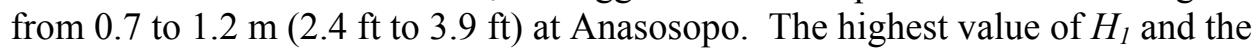


largest difference between $H_{1}$ and $H_{10}$ occur at the most exposed point on the Anasosopo line. At Aua and Leloaloa, $H_{1}$ exceeds $H_{10}$ by about 0.1 to $0.2 \mathrm{~m}$ (0.4 to $0.7 \mathrm{ft})$. At Anua, $H_{l}$ is very low, less than $0.1 \mathrm{ft}(0.03 \mathrm{~m})$ higher than $H_{10}$.

Relative to the berthing area criterion of wave heights not exceeding $0.3 \mathrm{~m}$ $(1 \mathrm{ft})$ more than 10 percent of the time, the Aua and Anua sites and the protected end of the Leloaloa line appear to be suitable locations for harbor docks. The $0.3-\mathrm{m}$ (1-ft) criterion is exceeded at the Anasosopo site and the more exposed part of the Leloaloa line, but these sites may also be suitable for some types of harbor operation. All four sites satisfy the $0.6-\mathrm{m}$ (2-ft) criterion. In comparing sites with each other and with past experience in the Pago Pago Harbor embayment, it is interesting to note that a severe event at Aua $\left(H_{l}\right)$ is comparable, in general, to the more frequently occurring $H_{10}$ at Leloaloa. Similarly, a severe event at Leloaloa, $H_{1}$, is comparable to $H_{10}$ at Anasosopo.

\section{Wave and Water Levels for Design}

Wind wave and swell results from CGWAVE model runs in this study were combined with extreme wave and water level modeling in a concurrent study of hurricane-induced stage-frequency relationships along the coast of American Samoa to provide information useful for design (Militello, Scheffner, and Thompson 2002). That study is summarized in the following paragraphs and results are presented for the four study sites.

Hurricane wind and wave growth models were run to produce deepwater wave hindcasts for 31 hurricanes impacting American Samoa during the years 1959 through 93 . For each hurricane, the time-history of hourly deepwater significant wave height, peak spectral period, and peak direction was saved at points around Tutuila, including a point representative of the seaward boundary of the CGWAVE domain. The deepwater wave time-history was transformed to a nearshore wave time-history at selected points along the 33-ft (10-m)-depth contour in the Pago Pago Harbor embayment. The approach involved calculating and applying spectral amplification factors, as discussed in the previous section. This approach does not take into account wave breaking and other energy dissipation processes that would affect extreme waves more than waves in the general climate. Waves at $33-\mathrm{ft}(10-\mathrm{m})$ depth are representative of waves incident to the nearshore fringing reef.

For each hurricane, the time-history of water level at the shoreline was calculated to include storm surge, ponding on the reef (due to incident waves breaking on the reef face), and nearshore wave setup. Some hurricanes had no appreciable impact on the study areas, while a few had a strong impact. The most extreme wave and water level conditions were from Hurricane Val, a powerful storm in December 1991 passing across Tutuila Island south of Pago Pago Harbor.

The highest water level at the shoreline from each of the 31 storms provided information for extreme water level analysis. The Empirical Simulation Technique was used to calculate water level at the shoreline for various return 
periods (Scheffner et al. 1999). Results for the four sites in this study are given in Table 7. Information includes the five highest significant wave heights producing storm-maximum water levels, peak wave period for the highest significant height, and water levels at the shoreline for various return periods. Water levels include storm surge, ponding on the reef, and nearshore wave setup.

\begin{tabular}{|l}
\hline \hline \multirow{2}{|l|}{$\begin{array}{l}\text { Table } 7 \\
\text { Extreme Wave and Water Levels }\end{array}$} \\
\hline \hline
\end{tabular}




\section{Harbor Oscillations}

To evaluate harbor resonance characteristics, the CGWAVE numerical model was run for the existing harbor. Incident longwave periods ranged from $25 \mathrm{sec}$ to $1,000 \mathrm{sec}$ in very fine increments, as discussed in Chapter 3 . These evaluations were included because oscillations can be an important part of interpreting the harbor wave response and identifying suitable alternative harbor sites. Amplification factor results are presented in the following section. Discussion of the results relative to operational performance criteria is given in the final section of this chapter.

\section{Amplification Factors}

\section{Background}

Amplification factors for the long waves involved in harbor oscillation behave differently than those for wind waves and swell. Long waves, because of their length relative to harbor dimensions and their reflectivity from harbor boundaries, form standing wave patterns in the harbor. Standing wave behavior in a simple closed basin of uniform depth is illustrated in Figure 17. In the fundamental mode of oscillation, antinodes occur at both basin walls and a node midway between walls. The distance between walls is equal to one-half of the oscillation wavelength. Second and third modes of oscillation are also illustrated. Antinodes always occur at the walls. Additional antinodes and nodes occur at regular intervals between walls, with the number of antinodes and nodes dependent on the mode of oscillation.

The water surface in a standing wave has its greatest vertical motion at antinodes. There is no vertical movement at an ideal node, but horizontal velocities reach a maximum there. In terms of amplification factors, $A_{a m p, l}$, this behavior gives large values of $A_{a m p, l}$ at antinodes and small values around nodes. Contrary to wind waves and swell, small values of $A_{a m p, l}$ are not necessarily indicative of a tranquil harbor area.

Phases in a standing wave also behave differently than for typical wind waves and swell. For example, the water surface in the fundamental mode of oscillation in Figure 17 simultaneously reaches a maximum at every point to the left of the node. These points are all in phase. At the same time, every point to the right of the node reaches a minimum value. These points are also in phase 


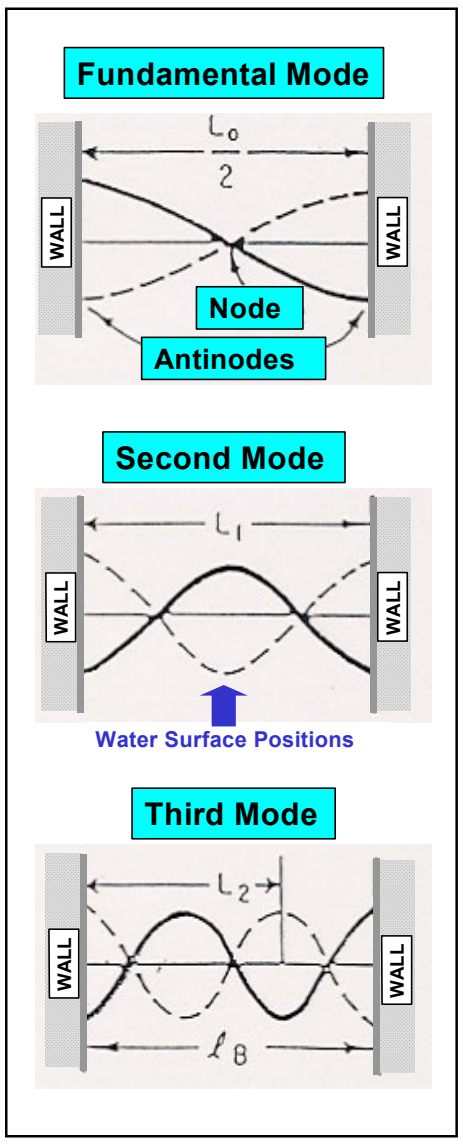

Figure 17. Harbor oscillation definitions with each other but exactly out of phase with the points to the left of the node. Thus, phases in a simple standing wave are constant between an antinode and node. They quickly change by $180 \mathrm{deg}$ (or $\pi$ radians) across the node and remain constant up to the next node or boundary.

\section{Alternative harbor sites}

Amplification factors for alternative harbor sites in the Pago Pago Harbor embayment are shown as a function of wave frequency in Figure 18. The amplification factor shown at each frequency and site is the maximum value for all output points along the length of the site. Some frequencies produce a strong resonant amplification, with peak $A_{\text {amp }, l}$ values higher than 10 , even exceeding 20 in two cases. Some of the same resonant frequencies appear at more than one site, though the strength of amplification can vary considerably.

Nine of the highest resonant peaks were selected to illustrate oscillation patterns in the harbor. These peaks are numbered in Figure 18 for easy reference. In amplification factor plots, areas of high amplification are evident as orange and red colors (Figures 19 through 21).

Corresponding phase contours are shown in

Figures 22-24. Areas in which $A_{a m p, l}$ is near zero and phase contours are tightly bunched indicate nodal zones. Relatively strong currents would occur across nodal lines during resonance events. The phase plots also indicate areas of the harbor which rise and fall together during the resonant condition (areas with the same color). Thus the oscillation patterns can be interpreted.

The 649.4-sec resonance (Peak 1) is primarily rocking between the inner Pago Pago Harbor embayment and the outside basin formed between the entrance and Taema Bank. Amplification factors in the funnel-shaped western end of Pago Pago Harbor, including the Anua site, become very high. The node for this oscillation runs from Tulutulu Point to the Anasosopo site.

The 454.6-sec resonance (Peak 2) also produces high amplification factors at the west end of Pago Pago Harbor. However, the node for this oscillation has moved further into the embayment to extend from Goat Island Point north near the Leloaloa site. Another antinode lies in the outer part of the Pago Pago Harbor embayment, giving rise to high amplification factors in the notch between Tulutulu Point and Niuloa Point. 


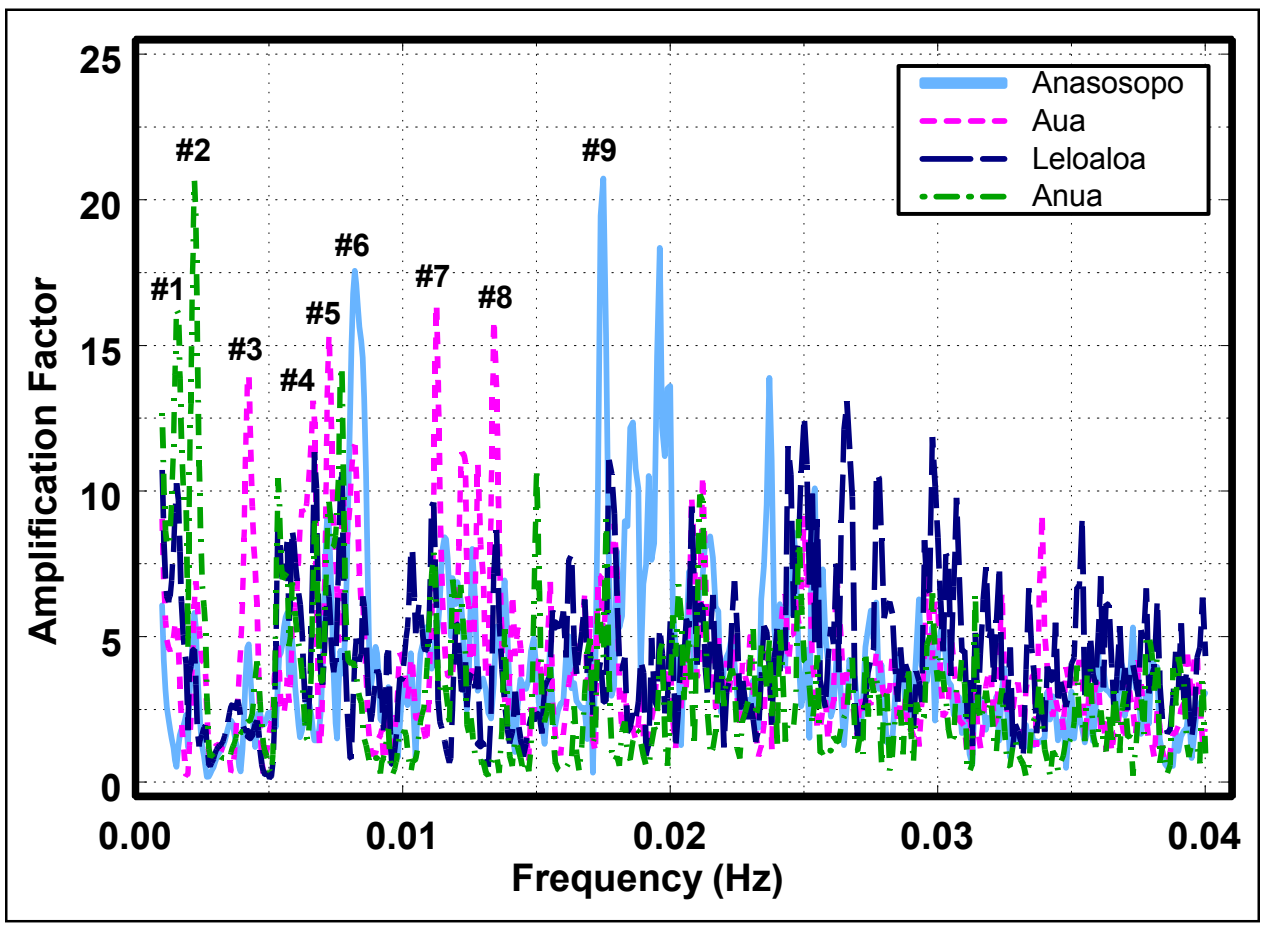

Figure 18. Longwave response, existing harbor

The shorter period oscillations are more complex patterns. They represent resonant oscillations between smaller-scale embayment features. For example, the 235.9-sec resonance (Peak 3) indicates rocking between the area around Tulutulu Point and the Aua site. The 149.3-sec resonance (Peak 4) suggests four nodes between the west end of Pago Pago Harbor and the Aua site. The 122.0-sec resonance (Peak 6) shows two nodes between Aua and the notch between Goat Island Point and Tulutulu Point.

Longwave amplification factors shown here may be overestimated for resonant peaks at periods less than about $100 \mathrm{sec}(0.01-\mathrm{Hz}$ frequency). Wave reflection coefficient at all solid boundaries was set to 1.0 for all longwave runs, but comparison of model results to field data in a previous study showed that peaks at the shorter longwave periods tend to be overestimated (Thompson et al. 1996). Some reduction in reflection coefficient as wave period decreases could be expected physically. Thompson et al. (1996) demonstrated that even a small decrease in reflection coefficient to $K_{r}=0.95$ can reduce resonant peaks dramatically. With no well-established basis for specific $K_{r}$ values as a function of long wave period and no provision in the model for conveniently incorporating a varying $K_{r}$, it was not practical to refine $K_{r}$ values in this study. As in previous studies, runs with $K_{r}=1.0$ were considered adequate for evaluating alternative sites. 


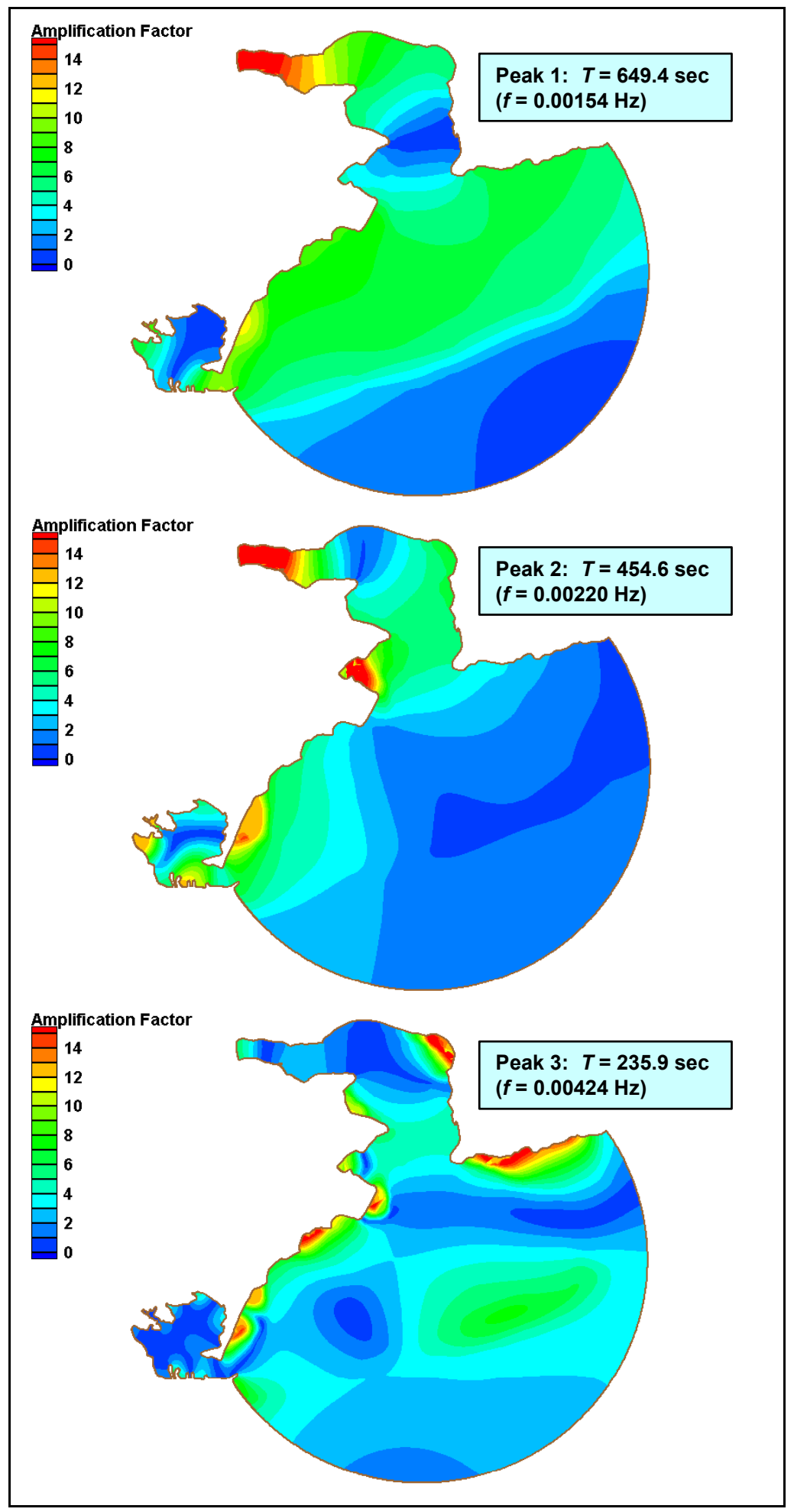

Figure 19. Resonant longwave amplification factor contours, Peaks 1-3 


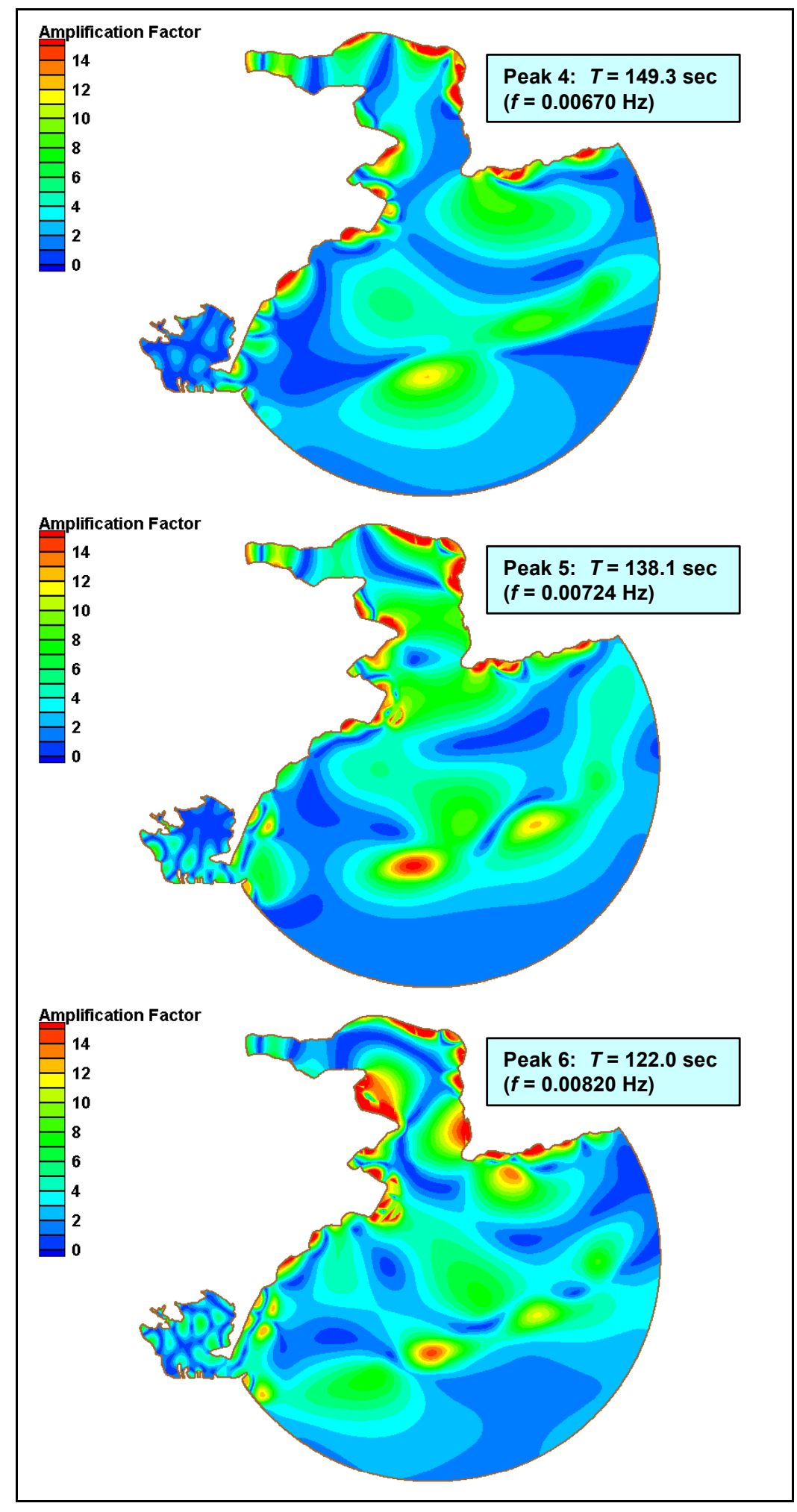

Figure 20. Resonant longwave amplification factor contours, Peaks 4-6 


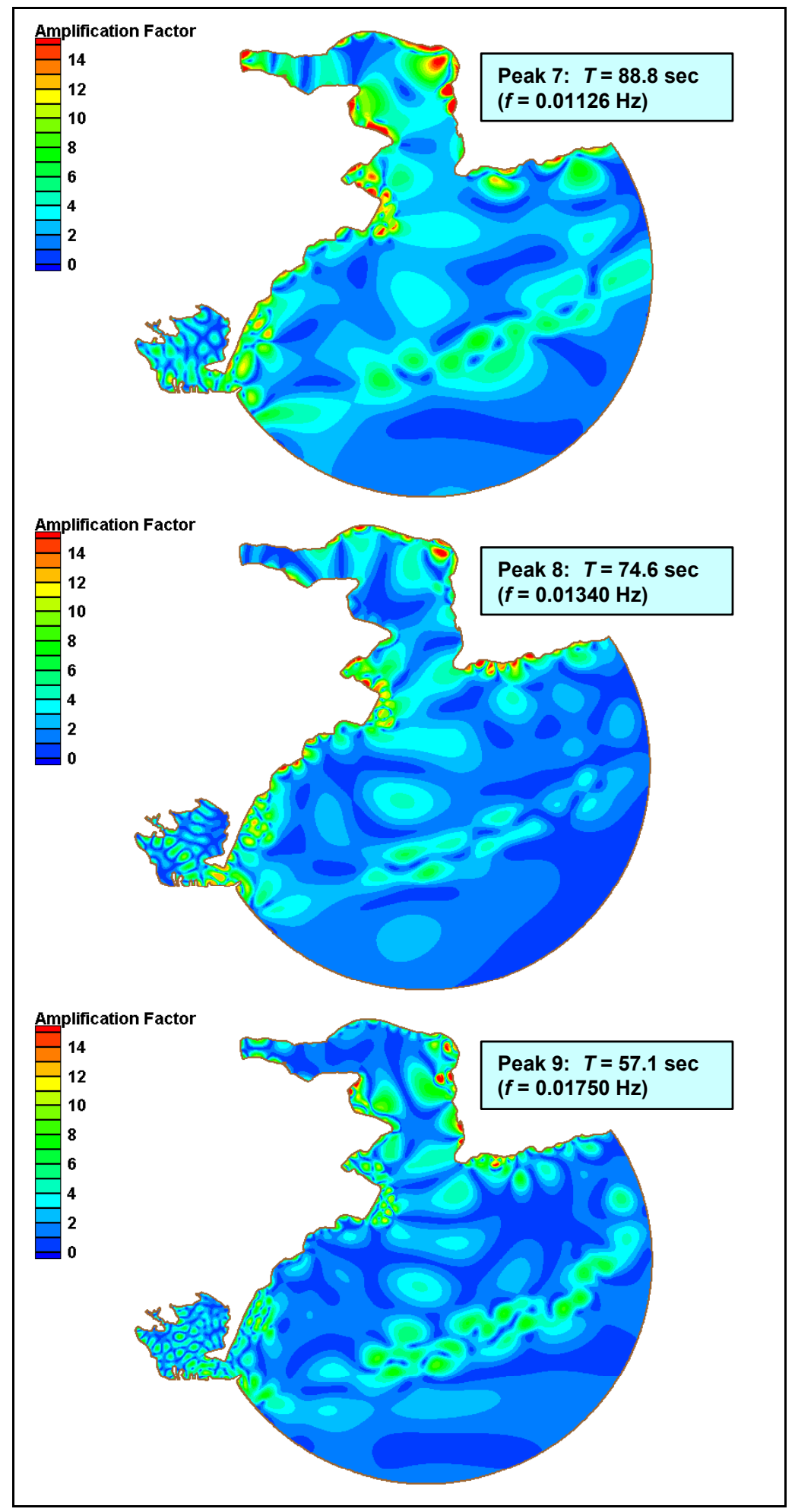

Figure 21. Resonant longwave amplification factor contours, Peaks 7-9 


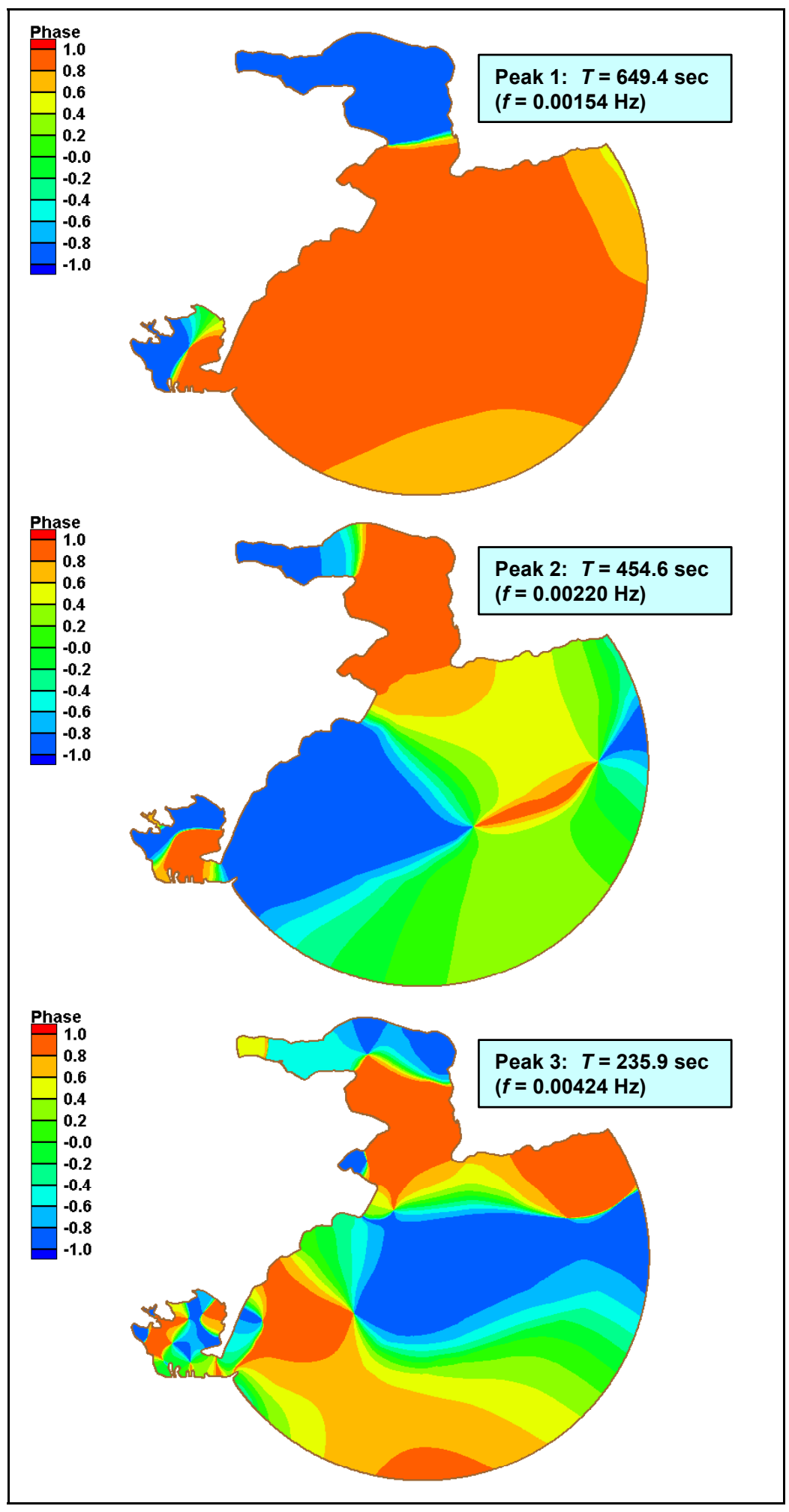

Figure 22. Resonant longwave phase contours, Peaks 1-3 


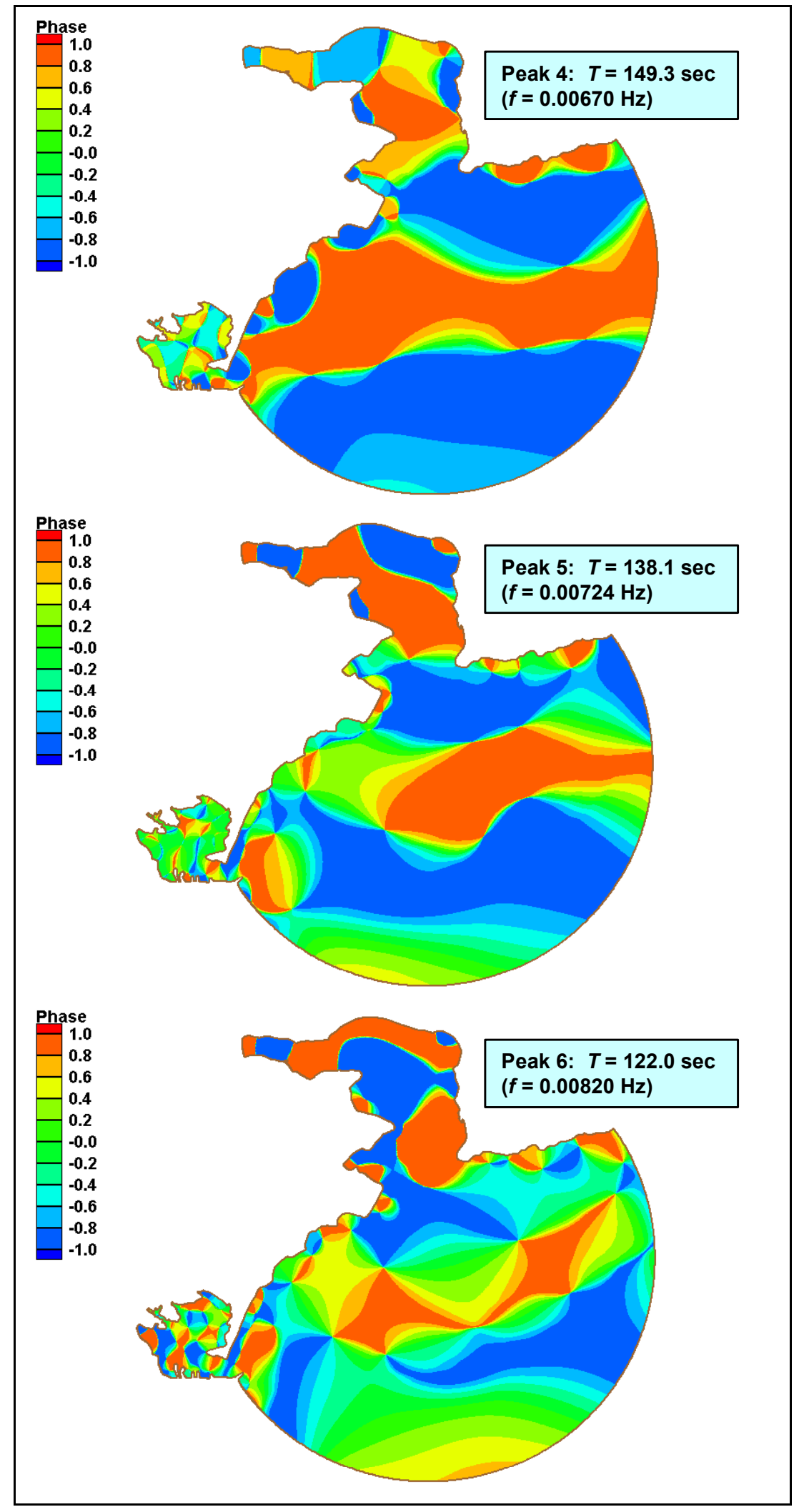

Figure 23. Resonant longwave phase contours, Peaks 4-6 


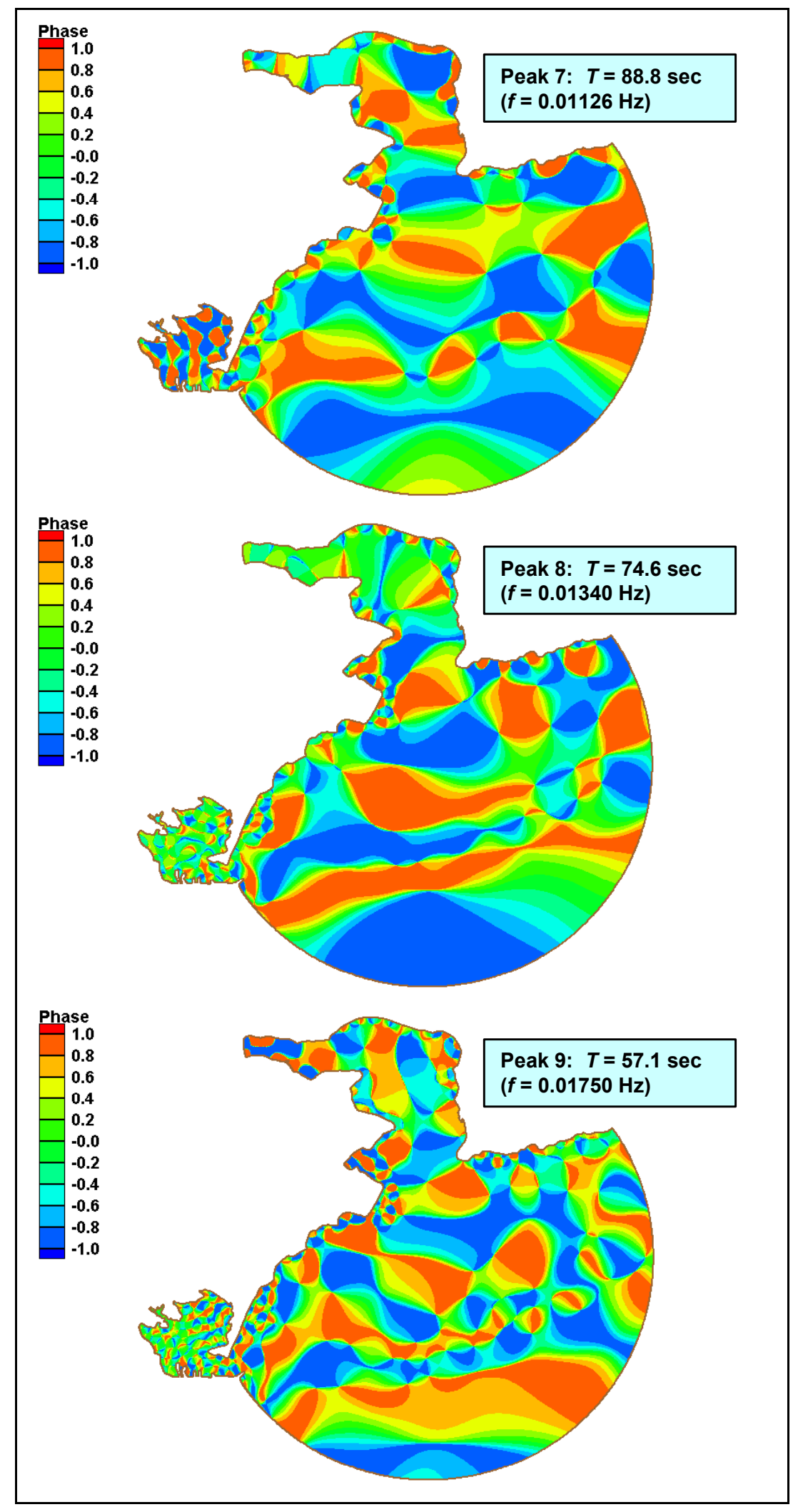

Figure 24. Resonant longwave phase contours, Peaks 7-9 


\section{Evaluation against Operational Criteria for Long Waves}

Procedures for evaluating the operational acceptability of different harbor plans subjected to long waves were reviewed by Thompson, Boc, and Nunes (1998). Two guidelines are applied in this study, as discussed in the following paragraphs. Each guideline provides a different and useful perspective on the long wave response of the various harbor sites.

One operational guideline is based on the value of $A_{\text {amp }, l}$ for the higher resonant peaks. Experience with Los Angeles and Long Beach harbors has indicated that if $A_{\text {amp }, l}$ is greater than about 5, some operational difficulties may be encountered. If $A_{a m p, l}$ is greater than 10, major operational problems can be expected (Seabergh, personal communication). This guideline may be applied to the plots of $A_{a m p, l}$ versus frequency. Based on this metric, the Leloaloa site would be the most suitable site, but major operatonal problems might be expected at all four sites and at existing docks.

Amplification factors computed in the Pago Pago Harbor embayment are significantly higher than what has been reported in past studies of successful harbors in other geographic locations. Despite the high amplification factors, the existing harbor is not known to experience operational problems because of longwave motions. To cause problems, harbor resonance periods would need to couple with a natural period of moored vessel motion, but vessels and mooring configurations in Pago Pago Harbor are not known to differ significantly from other commercial harbors.

Several possible factors can be considered to reconcile model results with experience in the existing harbor. First, the presence of fringing reefs over nearly the entire embayment is unusual relative to most harbors. The reefs may reduce reflectivity of harbor boundaries for long waves. Even a small reduction in reflection coefficient can have a major impact on resonant amplification factors. No data are available to assess this effect in the Pago Pago Harbor embayment. Second, the strength of resonant oscillations depends on both amplification factors and incident longwave heights. Since no long wave data are available in this geographic area, incident longwave heights are unknown. They may well be quite small for this south-facing coast exposed to relatively short-period waves. Past experience at locations in Hawaii and California exposed to swell from the north Pacific has shown that energy level in the 30 to 500 -sec period part of the long wave spectrum is directly correlated with energy level in the longer-period sea and swell wave conditions (Okihiro and Guza 1996; Briggs et al. 1994). Energy at periods longer than $500 \mathrm{sec}$ is attributed to forcing mechanisms other than swell, such as meteorological or atmospheric disturbances, internal waves, and tsunamis.

The second operational guideline relates to longwave velocity along the docks. PIANC (1995) gives criteria for maximum horizontal translational motions of moored vessels in terms of distance and velocity. Since horizontal motions are highly constrained by mooring lines, the velocity criteria seem more 
useful for present purposes (though they are stated to be applicable only for fishing vessels, coasters, freighters, ferries, and Ro-Ro vessels). The operational criteria for maximum velocity vary with size of ship, but they can be summarized as: maximum horizontal velocity less than 0.3 - to $0.6-\mathrm{m} / \mathrm{sec}(1-$ to $2-\mathrm{ft} / \mathrm{sec})$. Maximum velocity decreases as ship size increases, with $0.3 \mathrm{~m} / \mathrm{s}(1 \mathrm{ft} / \mathrm{sec})$ representing an 8,000-DWT ship and $0.6 \mathrm{~m} / \mathrm{sec}(2 \mathrm{ft} / \mathrm{sec})$ representing a 1,000-DWT ship.

Horizontal velocity was computed over the Pago Pago Harbor embayment for the nine selected resonant conditions (Figures 25 through 27). Velocity magnitude is directly related to longwave height. Longwave height was $10 \mathrm{~cm}$ $(0.3 \mathrm{ft})$ in the simulations, as in a recent study of Kahului Harbor (Thompson and Demirbilek 2002). Since velocities along existing docks significantly exceeded the PIANC criteria, velocities were scaled down to represent a $1-\mathrm{cm}(0.03-\mathrm{ft})$ incident longwave height, which produced velocities that are at least qualitatively consistent with the operability of existing docks. Although these are velocities of the water resulting from long wave motion rather than moored ship velocities (as in the PIANC criteria), they still provide a relevant metric for comparing harbor sites.

Horizontal velocity because of resonant oscillations in the Pago Pago Harbor embayment is strongly related to local water depth. The deeper areas consistently show velocities well below the PIANC criteria. Reef areas and the shallow Aua embayment show velocities exceeding the PIANC criteria for many of the resonant cases, especially the shorter period cases. For the 454.6 -sec resonance (Peak 2), velocities of about $0.3-$ to $0.6-\mathrm{m} / \mathrm{sec}(1-$ to $2-\mathrm{ft} / \mathrm{sec})$ are evident in most of the western tip of the harbor, including the Anua site.

Since three of the four alternative sites (Anasosopo, Aua, and Leloaloa) are adjacent to reef areas, they may be affected by strong velocities due to resonant oscillations. In practice, dock facilities in these areas which are sufficiently deep and offset from the reef may not experience operational difficulties due to long waves. 


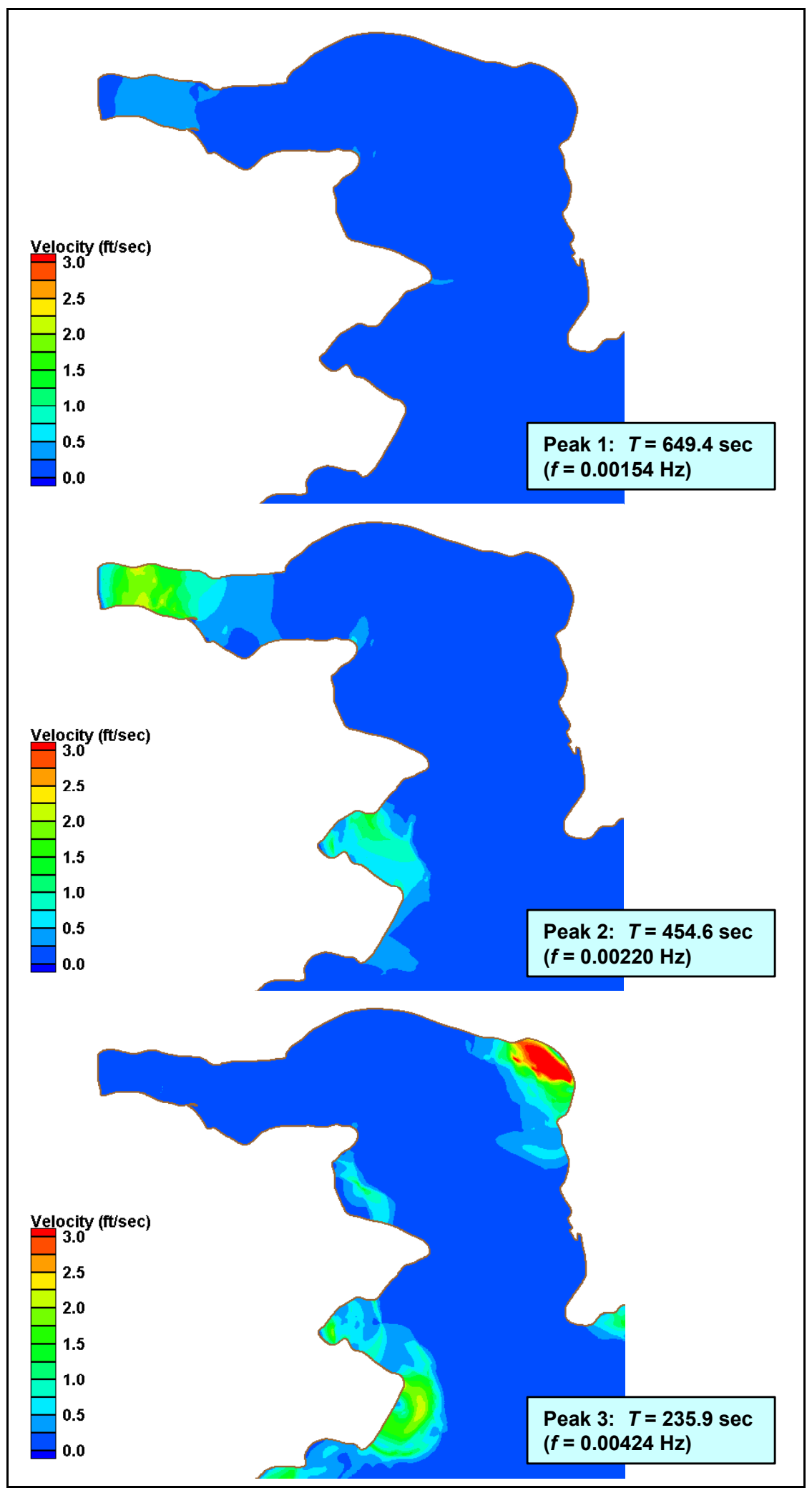

Figure 25. Resonant longwave velocity contours, Peaks 1-3 


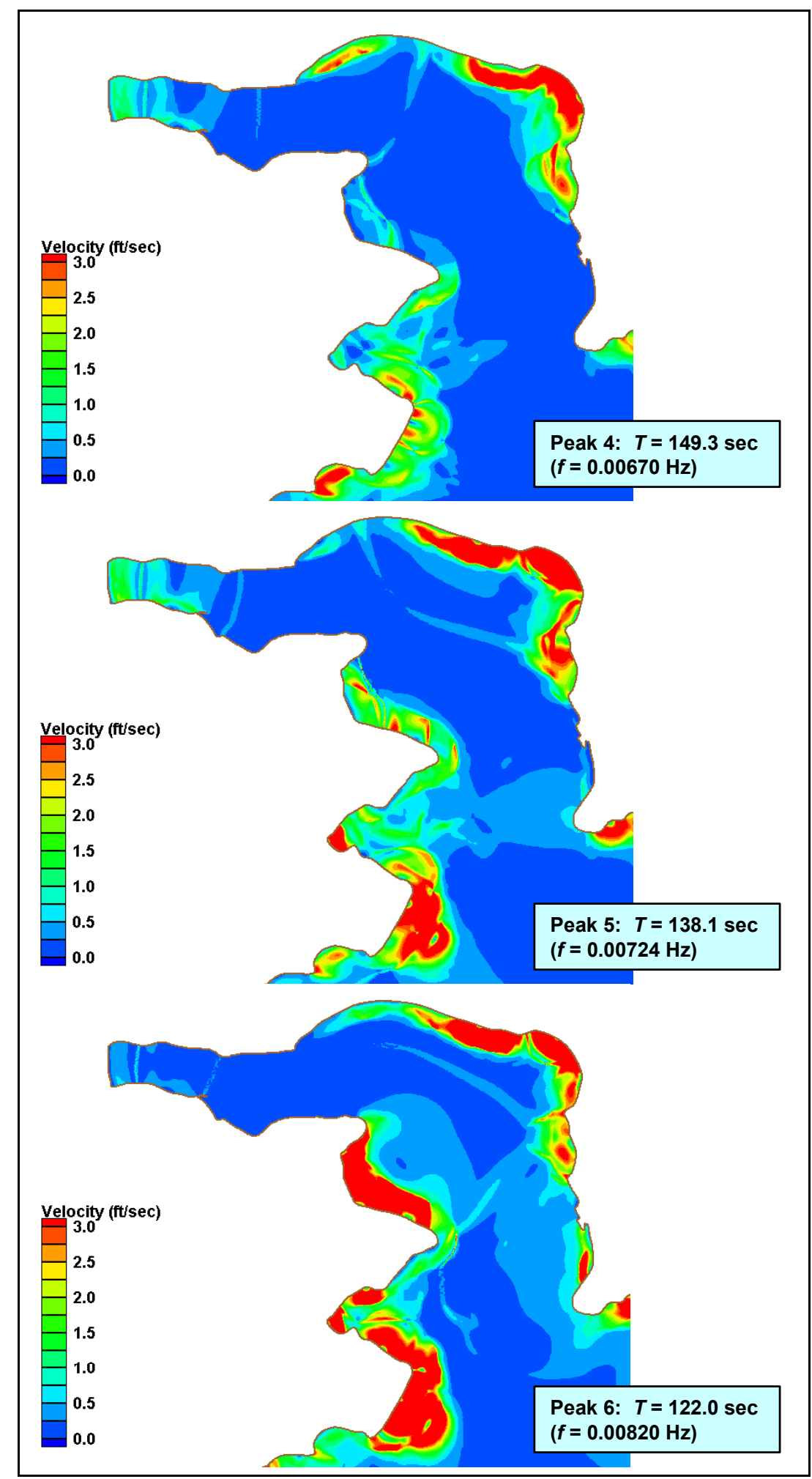

Figure 26. Resonant longwave velocity contours, Peaks 4-6 


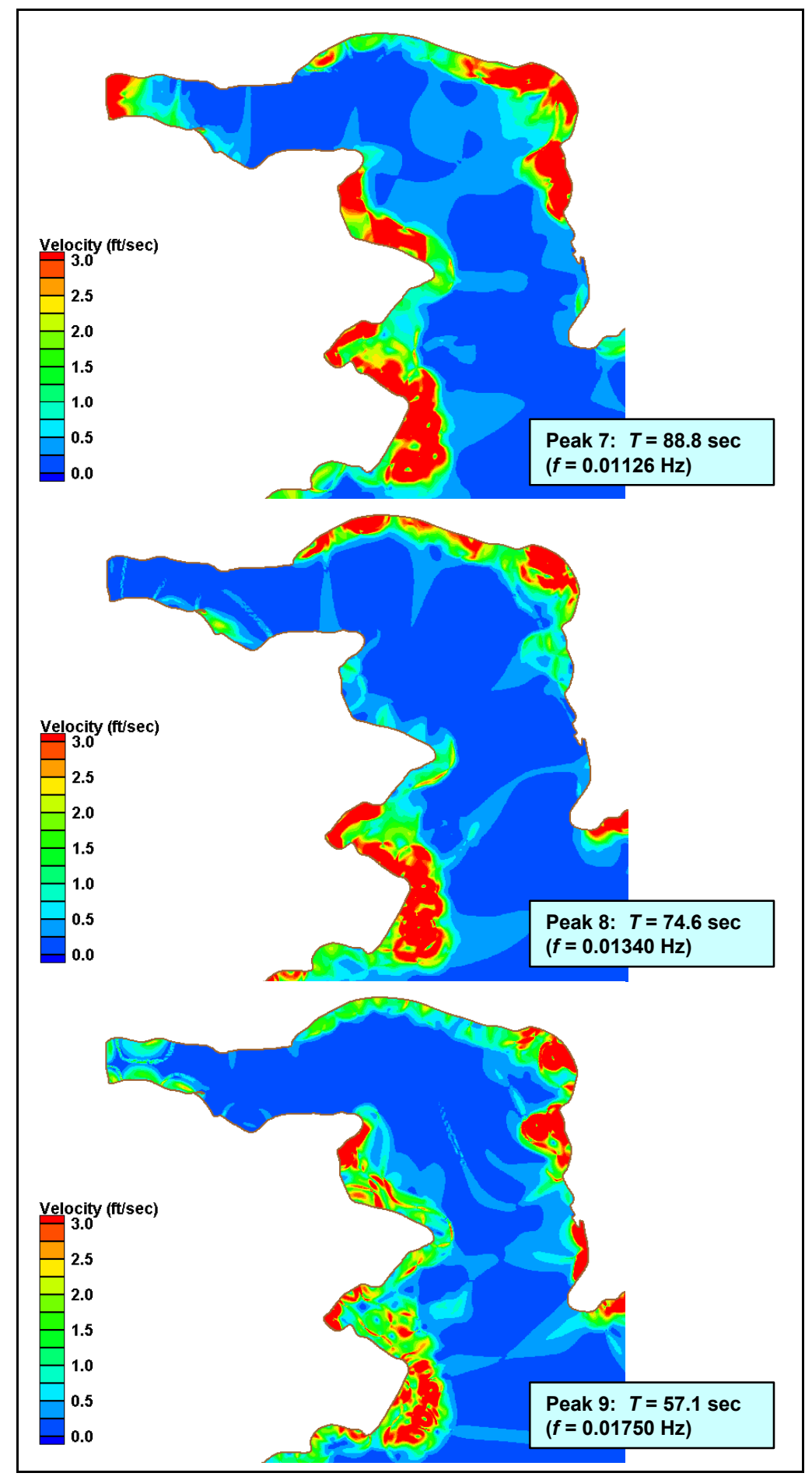

Figure 27. Resonant longwave velocity contours, Peaks 7-9 


\section{Conclusions and Recommendations}

Studies of the wave response of alternative sites for Pago Pago Harbor have produced information to assist in planning for future harbor facility requirements. The numerical model CGWAVE was used to simulate the behavior of the Pago Pago Harbor embayment, including four alternative harbor sites. Model results are compared with criteria for operational acceptability and with experience in the existing harbor to the extent possible. The effectiveness of proposed new harbor areas for wind wave and swell protection often has little relationship to protection from oscillations. These two aspects of pier operability are both considered in judging suitability of the alternative sites. Extreme wave and water level information for design is also presented.

Key input information for the study was available with varying degrees of accuracy. Detailed recent bathymetry was provided by HED for the entire Pago Pago Harbor embayment, including reef areas. The offshore wave climate incident to the study area was developed from summary tables of a 5-year hindcast of deepwater, open ocean waves near Western Samoa. This wave climate is expected to be reasonably representative but, if better definition of the incident wind wave and swell climate becomes available in the future, a more accurate assessment of the harbor sites will be possible. Very little information was available relative to long waves and this area appears to behave differently than more typical harbors studied previously. No data on incident longwave conditions exist, and no information about longwave response in Pago Pago Harbor embayment exists other than qualitative experience at existing docks. Thus, the long wave part of the study is primarily qualitative.

An overview of performance of the alternative sites is given by their success relative to a simple, meaningful criterion. For wind waves and swell, success was defined as having $H_{s}>0.3 \mathrm{~m}(1 \mathrm{ft})$ less than 10 percent of the time. This criterion is often used for small, shallow-draft vessel mooring areas, but it can also be a meaningful metric for operational suitability of deep-draft docks. A less demanding criterion, which may be more applicable to larger moored vessels, was also considered, namely $H_{s}>0.6 \mathrm{~m}(2 \mathrm{ft})$ less than 10 percent of the time. This secondary criterion may suffice, depending on the vessel types and sizes to be using the dock and the flexibility of their calling schedules. A similar overview of site performance for harbor oscillations could be developed only in relative terms, since quantitative longwave information was lacking. 
Specific conclusions and recommendations for each alternative site are as follows:

a. Anasosopo. Wind wave and swell heights are bigger than at the other sites but significantly reduced from offshore incident wave heights. The site satisfies the $0.6-\mathrm{m}$ (2-ft) criterion but does not meet the $0.3-\mathrm{m}$ (1-ft) criterion. The site is potentially impacted by resonant oscillations with periods of 50 to $60 \mathrm{sec}$ and $122 \mathrm{sec}$.

b. Aua. Wind wave and swell heights meet both the $0.6-\mathrm{m}(2-\mathrm{ft})$ and $0.3-\mathrm{m}$ (1-ft) criteria. A small bathymetric hump near the site causes a localized exceedance of the $0.3-\mathrm{m}(1-\mathrm{ft})$ criterion, but that issue could be addressed in detailed design of harbor facilities. The site is impacted by a number of resonant oscillation modes with periods between $75 \mathrm{sec}$ and $236 \mathrm{sec}$.

c. Leloaloa. Wind wave and swell heights meet the $0.6-\mathrm{m}(2-\mathrm{ft})$ criterion but do not meet the $0.3-\mathrm{m}(1-\mathrm{ft})$ criterion except at the more sheltered, west end of the site. This site is least likely to be adversely affected by harbor oscillations.

d. Anua. Wind wave and swell heights are negligible, far below the criteria. The site is potentially impacted by resonant oscillations with periods of $130,188,455$, and $649 \mathrm{sec}$.

These study results provide an assessment of potential harbor sites relative to short and longwave criteria. The modeling approach and evaluation criteria provide a useful basis for comparing alternative sites. However, more detailed studies are recommended at a later stage of planning and design. More detailed studies can take into account specific harbor designs and more attention to ship sizes and operations to be accommodated. Additional natural processes which may affect operations, such as wave-generated currents in reef areas, can also be evaluated in more detailed studies. 


\section{References}

Briggs, M. J., Lillycrop, L. S., Harkins, G. S., Thompson, E. F., and Green, D. R. (1994). "Physical and numerical model studies of Barbers Point Harbor, Oahu, Hawaii," Technical Report CERC-94-14, U.S. Army Engineer Waterways Experiment Station, Vicksburg, MS.

Demirbilek, Z., and Panchang, V. (1998). "CGWAVE: A coastal surface water wave model of the mild slope equation," Technical Report CHL-98-26, U.S. Army Engineer Waterways Experiment Station, Vicksburg, MS.

Kinhill, Riedel \& Byrne. (1992). "Emergency road rehabilitation project," Report EEP091/RP508 prepared for Government of Western Samoa, Victoria Park, Australia.

Millitello, A., Scheffner, N. W., and Thompson, E. F. (2002). "Hurricaneinduced stage-frequency relationships for the Territory of American Samoa," Technical Report CHL-02-01, U.S. Army Engineer Research and Development Center, Vicksburg, MS.

Okihiro, M. S., and Guza, R. T. (1996). "Observations of seiche forcing and amplification in three small harbors," Journal of Waterway, Port, Coastal and Ocean Engineering, American Society of Civil Engineers, 122(5), 232238.

PIANC. (1995). "Criteria for movements of moored ships in harbours, a practical guide," Report of Working Group No. 24, Supplement to Bulletin No. 88, Brussels, Belgium.

Scheffner, N. W., Clausner, J E., Militello, A., Borgmann, L E., Edge, B. L., and Grace, P. J. (1999). "Use and application of the empirical simulation technique: User's guide," Technical Report CHL-99-21, U.S. Army Engineer Research and Development Center, Vicksburg, MS.

Sea Engineering, Inc., and Belt Collins Hawaii. (1994). “American Samoa shoreline inventory update II," prepared for U.S. Army Corps of Engineers, Pacific Ocean Division, Fort Shafter, Hawaii 
Smith, J. M., Sherlock, A. R., and Resio, D. T. (2001). "STWAVE: Steadystate spectral wave model user's manual for STWAVE, Version 3.0," Special Report ERDC/CHL SR-01-1, U.S. Army Engineer Research and Development Center, Vicksburg, MS.

Thompson, E. F. (1980). "Energy spectra in shallow U.S. coastal waters," Technical Paper 80-2, U.S. Army Coastal Engineering Research Center, Vicksburg, MS.

Thompson, E. F., Boc, S. J., Jr., and Nunes, F. S. (1998). "Evaluating operational impact of waves along proposed harbor piers." Proceedings, Ports '98, ASCE and PIANC. Long Beach, CA, 8-11 March 1992.

Thompson, E. F., and Demirbilek, Z. "Wave climate and wave response, 2025 Plan, Kahului Harbor, Maui, Hawaii” (technical report in preparation), U.S. Army Engineer Research and Development Center, Vicksburg, MS.

Thompson, E. F., Hadley, L. L., Brandon, W. A., McGehee, D. D., and Hubertz, J. M. (1996). "Wave response of Kahului Harbor, Maui, Hawaii," Technical Report CERC-96-11, U.S. Army Engineer Waterways Experiment Station, Vicksburg, MS. 


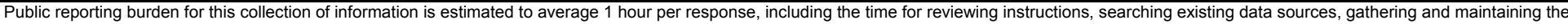

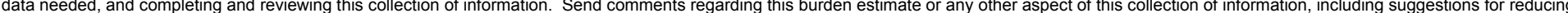

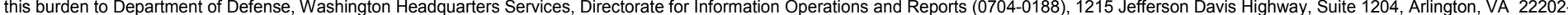

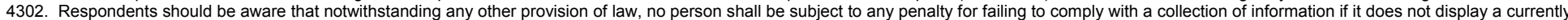
valid OMB control number. PLEASE DO NOT RETURN YOUR FORM TO THE ABOVE ADDRESS.

\begin{tabular}{l|l|l|l} 
1. REPORT DATE (DD-MM-YYYY) & 2. REPORT TYPE & 3. DATES COVERED (FrOm - To)
\end{tabular}

September 2002

Final report

\section{TITLE AND SUBTITLE}

Wave Response, Pago Pago Harbor, Island of Tutuila, Territory of American Samoa

6. AUTHOR(S)

Edward F. Thompson, Zeki Demirbilek

5a. CONTRACT NUMBER

5b. GRANT NUMBER

5c. PROGRAM ELEMENT NUMBER

5d. PROJECT NUMBER

5e. TASK NUMBER

5f. WORK UNIT NUMBER

7. PERFORMING ORGANIZATION NAME(S) AND ADDRESS(ES) AND ADDRESS(ES)

8. PERFORMING ORGANIZATION REPORT NUMBER

U.S. Army Engineer Research and Development Center

Coastal and Hydraulics Laboratory

ERDC/CHL TR-02-20

3909 Halls Ferry Road

Vicksburg, MS 39180-6199

9. SPONSORING / MONITORING AGENCY NAME(S) AND ADDRESS(ES)

10. SPONSOR/MONITOR'S ACRONYM(S)

U.S. Army Engineer District, Honolulu

Fort Shafter, HI 96858-5440

11. SPONSOR/MONITOR'S REPORT NUMBER(S)

\section{DISTRIBUTION / AVAILABILITY STATEMENT}

Approved for public release, distribution is unlimited.

\section{SUPPLEMENTARY NOTES}

\section{ABSTRACT}

The Pago Pago Harbor embayment is an extensive, naturally protected harbor area. The embayment includes Pago Pago commercial harbor, the principal harbor area of the Territory of American Samoa. To assist in planning for future harbor facility requirements, studies of the wave response of alternative sites in Pago Pago Harbor embayment were conducted. The numerical model CGWAVE was used to simulate the behavior of the Pago Pago Harbor embayment, including four alternative harbor sites. Model results were compared with criteria for operational acceptability and with experience in the existing harbor to the extent possible. The effectiveness of proposed new harbor areas for wind wave and swell protection often has little relationship to protection from oscillations. These two aspects of pier operability were both considered in judging suitability of the alternative sites. Extreme wave and water level information for design is also presented.

\section{SUBJECT TERMS}

Harbor resonance

Numerical modeling

Pago Pago Harbor
Territory of American Samoa

Tutuila Island

Wind waves and swell

\begin{tabular}{|c|c|c|c|c|c|}
\hline \multicolumn{3}{|c|}{ 16. SECURITY CLASSIFICATION OF: } & \multirow{2}{*}{$\begin{array}{l}\text { 17. LIMITATION } \\
\text { OF ABSTRACT }\end{array}$} & \multirow{2}{*}{$\begin{array}{l}\text { 18. NUMBER } \\
\text { OF PAGES } \\
\qquad 1\end{array}$} & \multirow{2}{*}{$\begin{array}{l}\text { 19a. NAME OF RESPONSIBLE PERSON } \\
\text { 19b. TELEPHONE NUMBER (include area } \\
\text { code) }\end{array}$} \\
\hline $\begin{array}{l}\text { a. REPORT } \\
\text { UNCLASSIFIED }\end{array}$ & $\begin{array}{l}\text { b. ABSTRACT } \\
\text { UNCLASSIFIED }\end{array}$ & $\begin{array}{l}\text { c. THIS PAGE } \\
\text { UNCLASSIFIED }\end{array}$ & & & \\
\hline
\end{tabular}

\begin{tabular}{|c|c|c|c|c|c|}
\hline \multicolumn{3}{|c|}{ 16. SECURITY CLASSIFICATION OF: } & \multirow{2}{*}{$\begin{array}{l}\text { 17. LIMITATION } \\
\text { OF ABSTRACT }\end{array}$} & \multirow{2}{*}{$\begin{array}{c}\text { 18. NUMBER } \\
\text { OF PAGES } \\
51\end{array}$} & 19a. NAME OF RESPONSIBLE PERSON \\
\hline $\begin{array}{l}\text { a. REPORT } \\
\text { UNCLASSIFIED }\end{array}$ & $\begin{array}{l}\text { b. ABSTRACT } \\
\text { UNCLASSIFIED }\end{array}$ & $\begin{array}{l}\text { c. THIS PAGE } \\
\text { UNCLASSIFIED }\end{array}$ & & & $\begin{array}{l}\text { 19b. TELEPHONE NUMBER (include area } \\
\text { code) }\end{array}$ \\
\hline
\end{tabular}

